\title{
Atkinson and Stiglitz Theorem with Endogenous Human Capital Accumulation
}

\author{
Hisahiro Naito* ${ }^{* \dagger}$ \\ Institute of Social and Economic Research \\ Osaka University \\ and \\ Department of Economics \\ University of California Irvine
}

Current version May, 2003

\begin{abstract}
Recently, several papers have re-examined the so called production efficiency theorem and the Atkinson and Stiglitz theorem on commodity taxes in the optimal taxation literature. Naito (1998) showed that indirect redistribution through production distortion or consumption distortion can Pareto-improve welfare and that the two theorems do not necessarily hold when different factors are imperfect substitutes and factor prices are endogenous. On the other hand, Saez (2001) argued that in the long run where human capital accumulation is endogenous, the two theorems are still valid. This paper points out that the result of Saez (2003) depends on the assumption on the dimension of the type of human capital. This paper shows that if different people have different comparative advantage in accumulating different types of human capital, the Atkinson and Stiglitz theorem does not hold.
\end{abstract}

Keywords: Human capital accumulation, non-linear income taxation and comparative advantage JEL Number: H21, H23

*I appreciate discussions at Public Economics Research Group around Osaka and Daiji Kawaguchi for his helpful information on the relationship between earnings and ability. Of course, the author is responsible for all remaining errors.

${ }^{\dagger}$ Address: Institute of Social and Economic Research, Osaka University, Mihogaoka 6-1, Ibaraki City, Osaka, Japan, postal code 567-0047

phone:81-6-6879-8581; fax: 81-6-6878-2766.

e-mail address: naito@iser.osaka-u.ac.jp 


\section{Introduction}

Whether efficient income redistribution should be done through income taxation alone or should be complemented with other measures such as production distortion or consumption distortion is one of the key issues whenever optimal public policies are discussed. With this regard, the production efficiency theorem (Diamond and Mirrlees, 1971), which states that production distortion is not optimal and the Atkinson and Stiglitz's result on optimal commodity taxation (Atkinson and Stiglitz, 1976, 1980), which shows that commodity taxation is not necessary in the presence of an income tax system, are the most important results in public finance literature.

Recently, in public finance literature researchers started examining those results. For example, Cremer, Pestieau and Rochet (2001) showed that the Atkinson and Stiglitz theorem does not hold when individuals are different in ability and endowment. Saez (2003) showed that the Atkinson and Stiglitz theorem does not hold when tastes are heterogenous. Naito (1999) showed that in a model similar to the model of Stiglitz (1982), if multiple goods are produced and factor prices are endogenous, the Atkinson and Stiglitz theorem does not necessarily hold and the production efficiency result does not either. On the other hand, Saez (2003) argued that when human capital accumulation is endogenous, then the Diamond and Mirrlees theorem and the Atkinson and Stiglitz theorem still hold.

In this paper, we show that the Atkinson and Stiglitz theorem does not hold even if human capital accumulation is endogenous contrary to Saez (2003). Consider a standard Harberger model and assume that there are skilled human capital intensive sector and unskilled human capital intensive sector. In this economy, if the government imposes a commodity tax on skilled human capital intensive good, then the return from skilled human capital will decrease and the return from the unskilled human capital will increase. Saez (2003) showed in this situation an indirect redistribution through the changes of the return from the skilled and unskilled human

capital is redundant when human capital accumulation is endogenous. However, the analysis of Saez (2003) assumes that the types of human capital is one dimensional. In reality, different 
people have different comparative advantage in accumulating different types of human capital. The present paper shows that in the presence of comparative advantage, the Atkinson and Stiglitz theorem does not hold even if human capital is endogenous.

To illustrate the basic idea, consider a situation where people with higher ability have comparative advantage in accumulating skilled human capital and people with lower ability have comparative advantage in accumulating unskilled human capital. Also, assume that the government cannot observe individual accumulated human capita but can observe only income level. For example, when an individual income is high, there are three possibilities: this individual is having high ability;this individual has a high level of skilled human capital;this individual has a very high level of unskilled human capital. But the government does not know which case applies to this individual. In this situation, a nonlinear income tax can be used for income redistribution, but the power of a nonlinear income tax is limited due to the unobservability of individual human capital levels and types. On the other hand, by imposing a commodity tax, the government can change the returns from skilled and unskilled human capital. Such indirect redistribution might complement an income tax when the individual level of human capital is unobservable.

The crucial assumption in the present paper is the presence of comparative advantage in human capital accumulation. Whether such an assumption is reasonable or not is an interesting empirical question. Earlier literature of the human capital theory assumed that earning could be explained completely once it is conditioned by human capital level. Earlier empirical evidences showed that there is a strong correlation between earnings and the level of human capital and indicated that ability does not matter for explaining earnings once they are conditioned by the human capital levels. On the other hand, recent literature of labor economics and self-selection emphasizes that ability can also increase earning and play a systematic role for explaining earnings even after it is conditioned by the human capital level. This literature points out that even in an extreme case when human capital does not increase the productivity at all, if ability can increase the productivity and if higher ability agents tend to acquire more skills, there will be a 
correlation between human capital level and earnings. In the standard signaling literature, it is commonly assumed that a higher ability person would get more benefit from acquiring skill. In addition, recently, Dinardo and Tobias (2001) and Tobias (2003) examined whether the returns from schooling are higher for high ability individuals than for low ability individuals by using a non-parametric method. They found that the returns are higher for high ability individuals than for low ability individuals. This suggests that assuming the presence of comparative advantage is not unrealistic as an approximation of the reality.

To prove that the Atkinson and Stiglitz theorem does not hold in a closed economy, we need to address several issues. In this paper, we assume that the economy is a closed economy in contrast to the case of proving that production inefficiency (Naito, 2003). This implies that the prices of goods and factors become endogenous and the effects of a commodity tax can be complex since factor supplies would also change. Second, when the factor prices are endogenous, it is well-known that the marginal income tax rate for some individual can be negative. In such a situation, it is not obvious that indirect redistribution through changes of the return from both skilled and unskilled human capital can increase the social welfare. Despite such questions, however, we prove that the Atkinson and Stiglitz theorem does not hold even when human capital is endogenous.

At this point, readers might wonder about the difference between Naito (2003) and the present paper. In Naito (2003), we assumed that the economy is open economy since our interest is on commercial policy. In an open economy, the commodity tax cannot affect the factor prices due to the famous factors rice equalization theorem (Samuelson 1949). Therefore, the Atkinson and Stiglitz theorem is valid. In contrast, in a closed economy, the commodity tax can affect the factor prices. Thus, we analyze the Atkinson and Stiglitz theorem in a closed economy.

The organization of this paper is as follows. In the next subsection, we shows the main result by assume that two types of human capital are perfect substitute in the utility function. Then, we analyze the case when two types of human capital are imperfect substitutes. In section 3 , we 
briefly make conclusions.

\section{Analysis}

\subsection{The basic model}

The economy is a closed economy where there are two output goods: good 1 and good 2. Good 1 is skilled human capital intensive good and good 2 is unskilled human capital intensive good. We assume that there are two types of human capital in this economy: skilled human capital and unskilled human capital. We assume that two types of human capital is perfect substitute in the utility function. This implies that people accumulate only one type of human capital. Besides the reason mentioned in the previous section, conducting a welfare analysis when individual behavior includes a discrete choice is useful from a theoretical standpoint as well. In many important economic situations such as the choice of location to live, the choice of technology by firms and labor market participation, decisions made by consumers or firms include discrete choices. Until very recently, welfare analysis that includes discrete choices was rare. As far as the author knows, only Boadway and Cuff (2001) started to investigate this issue very recently. They analyzed an optimal taxation problem when some individuals are bunched at the bottom. Another purpose of this section is to contribute to such a literature as well. As for individuals, there are a continuum of agents and all agents have identical, additive separable utility functions with respect to consumption, skilled human capital investment and unskilled human capital investment. We index all individuals' ability by $i$ where $i$ takes any value from one to two. We assume that the utility function of type $i$ agent has the following form:

$$
u\left(c_{1 i}, c_{2 i}\right)-a^{s} h_{i}^{s}-a^{u} h_{i}^{u}
$$

where $u\left(c_{1 i}, c_{2 i}\right)$ is strictly increasing with each argument and strictly concave. We assume that the utility function is homothetic. This implies that the demand function does not depend on income distribution of this economy. This assumption simplifies the analysis substantially. We assume that the labor supply is fixed and it is normalized to one. $h_{i}^{s}$ and $h_{i}^{u}$ are the level of 
skilled and unskilled human capital of individual $i . h_{i}^{s}$ and $h_{i}^{u}$ can be interpreted as the knowledge levels, years of education, experience and training for each type of skill. Given the amount of skilled human capital and unskilled human capital of individual $i$, we assume that the earning of individual $i$ is determined as

$$
\text { earning }_{i}=g_{s i} \times w^{s} \times h_{i}^{s}+g_{u i} \times w^{u} \times h_{i}^{u}
$$

where $w^{s}$ and $w^{u}$ are the returns from one efficient unit of skilled and unskilled human capital, respectively. (1) means that when individual $i$ accumulates $h_{i}^{s}$ units of skilled human capital and $h_{i}^{u}$ units of unskilled human capital, the efficient unit of skilled human capital and unskilled human capital are $g_{s i} \times h_{i}^{s}$ and $g_{u i} \times h_{i}^{u}$ and the total return from skilled human capital and unskilled human capital are $g_{s i} \times w^{s} \times h_{i}^{s}$ and $g_{u i} \times w^{u} \times h_{i}^{s}$, respectively. Let $g_{s i} \times w^{s}$ and $g_{u i} \times w^{u}$ be $w_{i}^{s}$ and $w_{i}^{u}$. Denote $\left(d g_{j i} / d i\right)$ as $g_{j i}^{\prime}$ where $\mathrm{j}=\mathrm{s}, \mathrm{u} . g_{s i}^{\prime} / g_{s i}$ and $g_{u i}^{\prime} / g_{u i}$ measure the absolute advantage of an agents with ability $i+\epsilon$ over agent $i$ in accumulating skilled human capital and unskilled human capital, respectively. We assume that agents who have higher ability have absolute advantage in accumulating both skilled human capital and unskilled human capital: $g_{s i}^{\prime} / g_{s i}>0$ and $g_{u i}^{\prime} / g_{u i} .{ }^{1}$ Also, as we discussed in the introduction, we assume that agents who have higher ability have comparative advantage in accumulating skilled human capital than unskilled human capital. Thus, we assume that

$$
\frac{g_{s i}^{\prime}}{g_{s i}}>\frac{g_{u i}^{\prime}}{g_{u i}}
$$

The economic meaning of the above equation is that as ability becomes higher, the return from accumulating skilled human capital becomes lager than the return from accumulating unskilled human capital.

As for the objective of the government, we assume that the social planner will maximize the following utilitarian social welfare function:

\footnotetext{
${ }^{1}$ The assumption of the absolute advantage is not necessary. The assumption of the absolute advantage is an sufficient condition that guarantees that agents who have higher $i$ will receive higher utility. As long as agents with higher ability can receive higher utility the assumption of the absolute advantage is not necessary.
} 


$$
\int_{1}^{2}\left\{u\left(c_{1 i}, c_{2 i}\right)-a^{s} h_{i}^{s}-a^{u} h_{i}^{u}\right\} n_{i} d i
$$

As for prices, we normalize the producer price and the consumer price of good 2 to one. Let $p_{1}$ and $t$ be the producer price of good 1 and the specific tax on good 1 . Then, the consumer price of good 1 is $p_{1}+t$.

For production side, we assume the standard Harberger model. In this economy, there are two sectors. The sector 1 is the skilled human capital intensive sector and it produces good 1. The sector 2 is the unskilled human capital intensive sector and it produces good 2. Each sector uses both skilled and unskilled human capital. Consumers (workers) are perfectly mobile between two sectors. When an agent who has $h_{i}^{s}$ units of skilled human capital and $h_{i}^{u}$ units of unskilled human capital works in sector $k$, it means that sector $k$ uses $g_{s i} \times h_{i}^{s}$ units of skilled human capital and $g_{u i} \times h_{i}^{u}$ units of unskilled human capital. Each sector behaves as a price taker and maximizes its profit. Let $F^{k}\left(H_{k}^{s}, H_{k}^{u}\right)$ be the production function in sector $k=1,2$ where $H_{k}^{s}$ and $H_{k}^{u}$ are the total amount of skilled human capital and unskilled human capital used in sector $k$. We assume that $F^{k}\left(H_{k}^{s}, H_{k}^{u}\right)$ exhibits constant returns to scale and it is concave with respect to both arguments. Let $c^{k}\left(w^{s}, w^{u}\right)$ be the cost function in sector $k$ to produce one unit of output in sector $k$ when the returns of one efficient unit of skilled human capital and unskilled human capital are $w^{s}$ and $w^{u}$, respectively. When both good 1 and good 2 are produced at the equilibrium, $w^{s}$ and $w^{u}$ are determined

$$
p_{1}=c_{1}\left(w^{s}, w^{u}\right) \text { and } 1=c_{2}\left(w^{s}, w^{u}\right)
$$

From the Stolper -Samuelson theorem, $\partial w^{s} / \partial p_{1}>0$ and $\partial w^{u} / \partial p_{1}<0$.

The output of both goods are determined from the following factor market equilibrium conditions:

$$
\begin{aligned}
\frac{\partial c_{1}}{\partial w^{s}} y^{1}+\frac{\partial c_{2}}{\partial w^{s}} y^{2} & =H^{s}, \text { and } \frac{\partial c_{1}}{\partial w^{u}} y^{1}+\frac{\partial c_{2}}{\partial w^{u}} y^{2}=H^{u} \\
\text { where } H^{s} & =\int_{i^{*}}^{2} g_{s i} \times h_{i}^{s} \times n_{i} d i \text { and } H^{u}=\int_{1}^{i^{*}} g_{u i} \times h_{i}^{u} \times n_{i} d i
\end{aligned}
$$


$H^{s}$ and $H^{u}$ are the total skilled and unskilled human capital in this economy. Although the output of both goods can be calculated from equation (5), it is more useful to work on the production possibility frontier for analytical reasons. Let $H^{s}$ and $H^{u}$ be the total amount of skill human capital and unskilled human capital in this economy and define a production possibility frontier as $\Gamma\left(H^{s}, H^{u}\right)$. Since the production functions are concave and the factor intensity of the two sectors are different, the production possibility set is convex. The output of good 1 and good 2 are determined as the solution of the following constrained maximization problem:

$$
\max p_{1} y_{1}+y_{2} \quad \text { s.t. } \quad\left(y_{1}, y_{2}\right) \in \Gamma\left(H^{s}, H^{u}\right)
$$

Thus, we can think that the output of good 1 and good 2 can be thought as a function of $p_{1}$, $H^{s}$ and $H^{u}$. Let $Y^{1}\left(p_{1}, H_{u}, H_{u}\right)$ and $Y^{2}\left(p_{1}, H_{u}, H_{u}\right)$ be the output function of good 1 and good 2. At the optimum, the slope of production possibility set is equal to the relative producer price of good 1. Thus, we obtain $Y_{p}^{1} \equiv \partial Y^{1} / \partial p_{1}>0$. The Rybcyzynski theorem shows that $Y_{H^{u}}^{1} \equiv \partial Y^{1} / \partial H^{u}<0$ and $Y_{H^{s}}^{1} \equiv \partial Y^{1} / \partial H^{s}>0$. Similarly, for good 2, we have $Y_{p}^{2}<0, Y_{H^{s}}^{1}>0$, $Y_{H^{u}}^{1}<0$.

The prices in this economy are determined so that the output of good 1 and good 2 are equated to the demand for good 1 and good 2, respectively. On the other hand, to find the equilibrium price, it is easy to focus on the relative demand since the utility function is homothetic and the relative demand is independent of income level. Let $R D\left(p_{1}+t\right)$ is the relative demand of good 1. Because of the homotheticity of the utility function, it is independent of income level and $R D_{p} \equiv d R D / d p_{1}<0$. Let $R S\left(p_{1}, H^{s}, H^{u}\right)$ be the relative supply of good 1 . From the shape of the production possibility frontier and the Rybcyzynski theorem, we have $R S_{p} \equiv \partial R S / \partial\left(p_{1}+t\right)>0$, $R S_{H^{s}} \equiv \partial R S / \partial H^{s}>0, R S_{H^{u}} \equiv \partial R S / \partial H^{u}<0$. The equilibrium price is determined from the following equation:

$$
R D\left(p_{1}+t\right)=R S_{1}\left(p_{1}, H^{s}, H^{u}\right)
$$

From the above equation, the equilibrium price can be a function of $t, H^{s}$ and $H^{u}$. Thus we can write the price of good 1 as $p_{1}=p_{1}\left(t, H^{s}, H^{u}\right)$. Once the price of good 1 is determined, then the 
returns from skilled and unskilled human capital are determined by (4).

When two types of skill accumulation are perfect substitutes in the disutility function, the agent always solves the following constrained disutility minimization problem:

$$
\begin{aligned}
Z\left(w_{i}^{s}, w_{i}^{u}, R\right) & \equiv \min a_{s} h_{i}^{s}+a_{u} h_{i}^{u} \\
\text { st } R & =w_{i}^{s} h_{i}^{s}+w_{i}^{u} h_{i}^{u} \\
\text { where } w_{i}^{s} & =g_{s i} \times w^{s} \text { and } w_{i}^{u}=g_{u i} \times w^{u}
\end{aligned}
$$

In the above problem, for an agent with ability $i$, if $a_{s} / a_{u}<w_{i}^{s} / w_{i}^{u}$ he will accumulate only skilled human capital and if $a_{s} / a_{u}>w_{i}^{s} / w_{i}^{u}$, he will accumulate only unskilled human capital. Note that because of the assumption of comparative advantage (2), $w_{i}^{s} / w_{i}^{u}$ is an increasing function of $i$. Let $i^{*}$ be $i$ that satisfies $\left(w^{s} \times g_{s i}\right) /\left(w^{u} \times g_{u i}\right)=a_{s} / a_{u}$. Then, agents whose ability is greater than $i^{*}$ accumulate only skilled human capital and agents whose ability $i$ is less than $i^{*}$ accumulate only unskilled human capital. We assume that such $i^{*}$ is located within 1 and $2 .^{2}$ Given such $i^{*}$ ,$Z\left(w_{i}^{s}, w_{i}^{u}, R\right)$ is

$$
\begin{aligned}
& Z\left(w_{i}^{s}, w_{i}^{u}, R\right)=a^{s}\left(\frac{R}{w_{i}^{s}}\right) \text { for } i^{*} \leq i \leq 2 \\
& Z\left(w_{i}^{s}, w_{i}^{u}, R\right)=a^{u}\left(\frac{R}{w_{i}^{u}}\right) \text { for } 1 \leq i<i^{*} .
\end{aligned}
$$

Let $X(R)$ be an after-tax income schedule that the government designs. Then, each agent chooses his best $R$ to maximize $U\left(p_{2}, X(R)\right)-Z\left(w_{i}^{s}, w_{i}^{u}, R\right)$. Once $R$ is chosen, an agent chooses his optimal skill type and accumulates human capital to generate pre-tax income $R$. Let $\widetilde{v}(i)$ be the maximized value given the schedule $X(R)$ :

$$
\widetilde{v}(i) \equiv \max _{R} U\left(p_{1}+t, X(R)\right)-Z\left(w_{i}^{s}, w_{i}^{u}, R\right)
$$

where $U\left(p_{1}+t, X\right)$ is the indirect utility function when the price of good 1 is $p_{1}+t$ and income is $X$. For the analysis of the optimal schedule of $X(R)$, we assume that the schedule of

\footnotetext{
${ }^{2}$ This assumption is not so restrictive as the following reason. For example, if $i^{*}$ is greater than 2 , all agents will accumulate only unskilled human capital. However, the production needs both skilled and unskilled human capital. As a result, the return from skilled human capital will start to increase and the return from unskilled human capital will start to decrease. This implies that $i^{*}$ will start to decrease. This process will continue until some agents start to accumulate skilled human capital.
} 
$X(R)$ is a continuous function. Although it is possible that the optimal schedule of $X(R)$ is not continuous, the tax schedules of almost of all developed countries are continuous. When $X(R)$ is a continuous function, it is straightforward to show that $\widetilde{v}(i)$ is continuous with respect to $i$ from the theory of the maximum (Berge 1963). In addition, there is an interesting property on $\widetilde{v}(i)$ in the neighborhood of $i^{*}$ that turns out to be crucial for our result. The following lemma shows that property of $\widetilde{v}(i)$.

Lemma 1 When $i$ increases, the graph of $\widetilde{v}(i)$ has a counter-clockwise kink at $i^{*}$.

Proof. Let $\widetilde{v}_{s}(i)$ be the maximized utility of an agent with ability $i$ given the tax schedule when he can accumulate only skilled human capital. Also, let $\widetilde{v}_{u}(i)$ be the maximized utility of an agent with ability $i$ when he can accumulate only unskilled human capital. By the definition, the graph of $\widetilde{v}(i)$ is the upper envelope of $\widetilde{v}_{s}(i)$ and $\widetilde{v}_{u}(i)$ and $i^{*}$ is at the intersection between $\widetilde{v}_{s}(i)$ and $\widetilde{v}_{u}(i)$. This implies that there is a counter-clockwise kink at $i^{*}$ (See also Figure 1).

Now consider the problem of designing a nonlinear income tax system. Let $\left(R_{j}, X_{j}\right)$ be the pre-tax income and after tax income when an agent announces that his type is $j$. Then define $v(i)$ and $\widehat{v}(j ; i)$ as follows:

$$
\begin{aligned}
v(i) & =\max _{\{j\}} U\left(p_{1}+t, X_{j}\right)-Z\left(w_{i}^{s}, w_{i}^{u}, R_{j}\right) \\
\widehat{v}(j ; i) & =U\left(p_{1}+t, X_{j}\right)-Z\left(w_{i}^{s}, w_{i}^{u}, R_{j}\right)
\end{aligned}
$$

$v(i)$ is the maximized utility given the schedule of $\left(R_{j}, X_{j}\right)$ and $\widehat{v}(j ; i)$ is the indirect utility when agent $i$ announces that he is type $j$. The global incentive compatibility condition implies that type $i$ agent has an incentive to announce that he is type $i$ :

$$
i=\arg \max _{\{j\}} \widehat{v}(j ; i)
$$

Assuming the differentiability of $\left(X_{j}, R_{j}\right)$, the first order condition of the incentive compatibility condition is

$$
\left.\frac{\partial \widehat{v}(j, i)}{\partial j}\right|_{j=i}=\frac{\partial U}{\partial x} \frac{\partial x}{\partial j}-\frac{\partial Z}{\partial R} \frac{\partial R}{\partial j}=0
$$


On the other hand, by using the definition of $Z\left(w_{i}^{s}, w_{i}^{u}, R_{j}\right)$, we can calculate $d v(i) / d i$ for $i$ in $\left(1, i^{*}\right)$ and $\left(i^{*}, 2\right)$.

$$
\begin{aligned}
& \frac{d v}{d i}=a^{s} \frac{g_{s i}^{\prime}}{g_{s i}} \frac{R_{i}}{g_{s i} w^{s}} \text { for } i \in\left(i^{*}, 2\right) \\
& \frac{d v}{d i}=a^{u} \frac{g_{u i}^{\prime}}{g_{u i}}\left(\frac{R_{i}}{g_{u i} w^{u}}\right) \text { for } i \in\left(1, i^{*}\right)
\end{aligned}
$$

Next we will check a single crossing property of the utility function $U\left(p_{1}+t, X\right)-Z\left(R, w^{s}, w^{u}, R\right)$. The marginal rate of substitution between $X$ and $R$ is

$$
\begin{aligned}
\operatorname{MRS}(\mathrm{R}, \mathrm{X}) & =\frac{1}{U_{x}} \frac{a^{s}}{g_{s i} w^{s}} \text { for } i \in\left(i^{*}, 2\right) \\
& =\frac{1}{U_{x}} \frac{a^{u}}{g_{u i} w^{u}} \text { for } i \in\left(1, i^{*}\right)
\end{aligned}
$$

Thus the $\operatorname{MRS}(\mathrm{R}, \mathrm{X})$ is a decreasing function of $i$ and a single crossing property is satisfied. This means that the local incentive compatibility constraint (7) and (8) and the monotone condition of $R$ are sufficient conditions for the global incentive compatibility (6) (Fudenberg and Tirole, 1991). Through the analysis of this paper, we assume that the monotonicity constraint is not binding. ${ }^{3}$

Given the first order conditions of the incentive compatibility constraint of it is useful to think that the government controls $v(i)$ and $R_{i}$ and that $X_{i}$ is defined from the following relationship:

$$
v(i)=U\left(p_{1}+t, X\right)-Z\left(w_{i}^{s}, w_{i}^{u}, R_{j}\right)
$$

Let $x\left(R, v, p_{1}+t, w_{i}^{s}, w_{i}^{u}\right)$ be the solution that solves (9) about $X$. Obviously, $\partial x / \partial v=\left(U_{x}\right)^{-1}$ , $\partial x / \partial R_{i}=Z_{R} / U_{x}$ and $\partial x / \partial p=-\left(U_{p}\right) /\left(U_{x}\right), \partial x / \partial p=-\left(U_{p}\right) /\left(U_{x}\right), \partial x / \partial w_{i}^{s}=Z_{w_{i}^{s}} /\left(U_{x}\right)$ and $\partial x / \partial w^{u}=Z_{w^{u}} /\left(U_{x}\right)$.

Finally for analytical convenience, rewrite the first order condition of (7) and (8) :

$$
\dot{v}^{s}=\frac{g_{s i}^{\prime}}{g_{s i}} a^{s} h_{i}^{s} \quad \text { and } \quad \dot{v}^{u}=\frac{g_{u i}^{\prime}}{g_{u i}} a^{u} h_{i}^{u}
$$

\footnotetext{
${ }^{3}$ This assumption is equivalent to assuming that there is no bunching. Many of the previous papers assumed that there is no bunching at the optimum. (Konishi 1995, Naito 1998).
} 
Based on the setup, the purpose of the government is to solve the following programming problem:

$$
\begin{gathered}
W(t)=\max \int_{1}^{i^{*}} v^{u}(i) n_{i} d i+\int_{i^{*}}^{2} v^{s}(i) n_{i} d i \\
\text { st. } \quad \dot{v}^{s}=\frac{g_{s i}^{\prime}}{g_{s i}} a^{s} h_{i}^{s} \quad \text { for } i^{*}<i \leq 2 \\
\dot{v}^{u}=\frac{g_{u i}^{\prime}}{g_{u i}} a^{u} h_{i}^{u} \quad \text { for } 1<i<i^{*} \\
v^{s}\left(i^{*}\right)=v^{u}\left(i^{*}\right) \\
R_{i^{*}}^{s}=R_{i^{*}}^{u} \\
\int_{i^{*}}^{2}\left\{R_{i}^{s}-x\left(R_{i}^{s}, v_{i}^{s}, w_{i}^{s}, w_{i}^{u}, p_{1}+t\right)\right\} n_{i} d i \\
\int_{1}^{i^{*}}\left\{R_{i}^{u}-x\left(R_{i}^{u}, v_{i}^{u}, w_{i}^{s}, w_{i}^{u}, p_{1}+t\right)\right\} n_{i} d i \\
+t \int_{1}^{2} n_{i} c_{1 i} d i \geq 0 \\
H^{s}=\int_{i^{*}}^{2} h_{i}^{s} g_{s}(i) n_{i} d i, H^{u}=\int_{1}^{i^{*}} h_{i}^{u} g_{u}(i) n_{i} d i \\
\text { where } \\
p_{1}=p_{1}\left(t, H^{s}, H^{u}\right), v_{i}^{j}=v^{j}(i),
\end{gathered}
$$

The above programming problem deserves several comments. First, (IC1) and (IC2) are the local incentive compatibility constraints. Second, (BD1) comes from the assumption that the tax schedule that the government designs is continuous and, as a result, the utility level of the agents must be continuous. (BD2) comes from the assumption that individual $i^{*}$ chooses only one $R$. Now let $\mu_{i}^{s}, \mu_{i}^{u}$ and $\lambda$ be the Lagrangian multipliers of (IC1),(IC2) and (RC). Let $\beta_{1}, \beta_{2}, \beta_{s}$ and $\beta_{u}$ be the Lagrangian multipliers of (BD1), (BD2), (SHC) and (UHC). The first order conditions can be calculated and we will write them in the Appendix to save the space. Then, what we need to know is the effect of increasing $t$ from zero on the social welfare, which is equivalent to $d W / d t$. By using the envelope theorem, we have (See Appendix)

$$
\left.\frac{d W}{d t}\right|_{t=0}=\Psi_{1} \frac{d i^{*}}{d p_{1}}\left\{\mu_{i^{*}}^{s} a^{s} h_{i^{*}}^{s} \frac{g_{s}^{\prime}}{g_{s}}-\mu_{i^{*}}^{u} a^{u} h_{i^{*}}^{u} \frac{g_{u}^{\prime}}{g_{u}}\right\}
$$




$$
\text { where } \quad \Psi_{1}=\frac{-R D_{p}}{R D_{p}-R S_{p}+R S_{H^{s}} \frac{\partial i^{*}}{\partial p_{1}} g_{s i^{*}} h_{i^{*}}^{s}-R S_{H^{u}} \frac{\partial i^{*}}{\partial p_{1}} g_{u i^{*}} h_{i^{*}}^{u}}<0
$$

From the FOC of $v_{i^{*}}^{s}$ and $v_{i^{*}}^{u}$, we have $\mu_{i^{*}}^{s}=\mu_{i^{*}}^{u}$. In addition, as we show in the Appendix, $\mu_{i}^{s}$ and $\mu_{i}^{u}$ are positive. Furthermore $a^{s} h_{i^{*}}^{s}\left(g_{s}^{\prime} / g_{s}\right)$ and $a^{u} h_{i^{*}}^{u}\left(g_{u}^{\prime} / g_{u}\right)$ are the right hand slope of $v_{i}^{s}$ and the left hand slope $v_{i}^{u}$ at $i^{*}$. From Lemma 1, the slope of $v_{i}^{s}$ is steeper than the slope of $v_{i}^{u}$ at $i^{*}$. Since $\frac{d i^{*}}{d p_{1}}<0$, we have $d W / d t>0$.

Proposition 1 Suppose that the social planner designs a nonlinear income tax system to maximize the utilitarian social welfare function without a commodity tax. Then, introducing a commodity tax on an skilled human capital intensive good will increase the social welfare.

In the above equation (10), $\Psi_{1}$ shows a change of the price of good 1 when $t$ increases in a compensated way. ${ }^{4}$ Second, as for the meaning of the inside of the bracket in (10), it is useful to see Figure 1. In Figure 1, when the government increases the commodity tax $t$ from zero, the graph of $\widetilde{v}_{s}(i)$ will shift downward and the graph of $\widetilde{v}_{u}(i)$ shifts upward. As a result, $i^{*}$ will increase. Also, notice that from $(\mathrm{IC} 1)$ and $(\mathrm{IC} 2)$, the slope of $\widetilde{v}_{s}(i)$ increases and the slope of $\widetilde{v}_{u}(i)$ decreases. The inside of the bracket is the difference of the slops of two curves.

In the mechanism designs problem, $\dot{v}$, the slope of the value function, is related with how the compensation schedule must be sensitive with unobserved ability. When $\dot{v}$ is higher, it means that the social planner needs to give higher utility to those with higher ability. With redistributive social welfare function, the social planner wants to give higher utility to agents with lower ability. Thus, when $\dot{v}$ is high, the level of utility that the social planner can give to the agents with lower ability is limited since the amount of the resource is limited. In such a situation, if the government can make $\dot{v}$ smaller exogenously, it is possible to increase the social welfare and changing $t$ can be a good policy tool for changing $\dot{v}$.

\footnotetext{
${ }^{4}$ First note that the total skilled and unskilled human capital are functions of the price of good1. Thus, for a given level of the commodity tax, the equilibrium price can be determined from

$R S\left(t+p_{1}\right)=R S\left(p_{1}, H^{s}\left(p_{1}\right), H^{u}\left(p_{1}\right)\right)$. Second, $-\frac{\partial i^{*}}{\partial p_{1}} g_{s i^{*}} h_{i^{*}}^{s}$ and $\frac{\partial i^{*}}{\partial p_{1}} g_{u i^{*}} h_{i^{*}}^{u}$ are the compensated change of supply of skilled and unskilled human capital when the price of good 1 increases. Thus, we obtain $d p_{1} / d t=\Psi_{1}$
} 
When $t$ increases, the change of $\dot{v}$ is not the same for all individuals however. As Figure 1 shows, all individuals whose ability is lower than $i^{*}$ will experience a decrease of $\dot{v}$ and all individuals whose ability is greater than $i^{*}$ will experience an increase of $\dot{v}$ except the neighborhood of $i^{*}$. But, as the analysis in the Appendix shows, the effect of a change of $\dot{v}$ for those agents is of the second order and can be replicated by the adjustment of the nonlinear income system. On the other hand, there are some individuals who experience the first order change of $\dot{v}$. Individuals whose ability is in $\left(i^{*}, i^{*}+\left(d i^{*} / d p_{1}\right)\left(d p_{1} / d t\right)\right)$ will switch from accumulating skilled human capital to unskilled human capital. Since the graph of $v(i)$ has a counter-clockwise kink at $i^{*}$, individuals in $\left(i^{*}, i^{*}+\left(d i^{*} / d p_{1}\right)\left(d p_{1} / d t\right)\right)$ will experience the first order decrease of $\dot{v}$. This implies that the government needs less ability-sensitive compensation schedules for those agents. Because this change of $\dot{v}$ has the first order effect, it will increase the social welfare.

(10) can be interpreted in terms of the marginal tax schedule as well. Note that $\left(\partial Z / \partial R^{m}\right) / U_{x}$ is equal to $1-T_{i}^{m}$ where $T_{i}^{m}$ is the marginal tax rate of income of those who accumulated $m=s, u$ type of skill and his ability is equal to $i$. From the FOC of $R_{i}^{s}$ and $R_{i}^{u}$,

$$
\lambda n T_{i}^{s}=\mu_{i}^{s} \times a^{s} \frac{\partial h_{i}^{s}}{\partial R_{i}^{s}} \frac{g_{s}^{\prime}}{g_{s}} \text { and } \lambda n T_{i}^{u}=\mu_{i}^{u} \times a^{u} \frac{\partial h_{i}^{u}}{\partial R_{i}^{u}} \frac{g_{u}^{\prime}}{g_{u}}
$$

Thus, Since $(\partial h / \partial R) \times R=h$, we have

$$
\left.\frac{d W}{d t}\right|_{t=0}=\Psi_{1} \frac{d i^{*}}{d p_{1}} \lambda n\left(R_{i^{*}}^{s} T_{i^{*}}^{s}-R_{i^{*}}^{u} T_{i^{*}}^{u}\right)
$$

$T_{i^{*}}^{s}$ and $T_{i^{*}}^{u}$ are the marginal tax rates of individuals just above $i^{*}$ and just below $i^{*}$, respectively. When $t$ increases in a compensated way, the price of good 1 will increase by $\Psi_{1}$ taking the effect of the change of human capital into consideration. When the price of good 1 will increase, $i^{*}$ will change by $d i^{*} / \partial p_{1}$. Then, an individual just above $i^{*}$ who initially accumulated skilled human capital will switch from accumulating skilled human capital to unskilled human capital. Since the marginal tax rate of those who accumulated skilled human capital is higher than the marginal tax rate for those who accumulated unskilled human capital around $i^{*}$, the marginal tax rate will decrease. ${ }^{5}$ Thus, $R_{i^{*}}^{s} T_{i^{*}}^{s}-R_{i^{*}}^{u} T_{i^{*}}^{u}$ is the earning that is affected by a change of the marginal tax

\footnotetext{
${ }^{5}$ Readers still might wonder why the marginal tax rate for those who accumulated skilled human capital is
} 
rates. Since this change of the marginal tax rate is of the first order, it can increase the social welfare.

\section{$2.2 \quad$ A case of Imperfect Substitutes}

In the previous sub-section, we consider a case where two types of human capital are perfect substitutes. As a result, each person accumulates only one type of human capital. In reality, however, individual might accumulate both types of human capital. It is important to check the robustness of our proposition when two types of human capital are imperfect substitutes. In addition, in a model where two types of human capital are perfect substitutes, the income tax does not affect the decision regarding which type of human capital to accumulate. One way to make human capital accumulation depend on the income tax system is to assume that two types of human capital are imperfect substitutes.

In order to make two types of human capital are imperfect substitutes, we assume that the utility function of type $i$ agent has the following form:

$$
u\left(c_{1 i}, c_{2 i}\right)-f_{s}\left(h_{i}^{s}\right)-f_{u}\left(h_{i}^{u}\right)
$$

Regarding $u\left(c_{1 i}, c_{2 i}\right)$, we make the same assumption as in the previous section. As for $f_{j}\left(h_{i}^{s}\right)$ $(\mathrm{j}=\mathrm{s}, \mathrm{u}), f_{j}\left(h_{i}^{j}\right)$ is strictly increasing and strictly convex. The labor supply is fixed. In addition, to simplify the analysis, we assume that $f_{s}\left(h_{i}^{s}\right)$ and $f\left(h_{i}^{u}\right)$ have the following functional forms: ${ }^{6}$

$$
f_{s}\left(h_{i}^{s}\right)=\left(h_{i}^{s}\right)^{\gamma_{s}} \text { and } f_{s}\left(h_{i}^{u}\right)=\left(h_{i}^{u}\right)^{\gamma_{u}}
$$

where $\gamma_{s}$ and $\gamma_{u}$ measure the curvature of the disutility functions of skilled and unskilled human capital accumulation respectively and they are strictly greater than one. Given the amount of skilled human capital and unskilled human capital of individual $i$, we assume that the earning of individual $i$ is determined as we assumed in the previous subsection. Agents who have higher

higher than those who accumulated unskilled human capital around $i^{*}$. The reason is around the right hand side of $i^{*}$, the marginal return from ability is higher at the right hand side of $i^{*}$ than at the left hand side of $i^{*}$ because $i^{*}$ is a switching point.

${ }^{6}$ Our main results can hold in more general functional forms. 
ability have comparative advantage in accumulating skilled human capital than unskilled human capital. More specifically, we assume that

$$
\frac{g_{s i}^{\prime}}{g_{s i}}>\frac{g_{u i}^{\prime}}{g_{u i}} \frac{\gamma_{u}}{\gamma_{s}}
$$

(11) implies that when the disutility of accumulating human capital is not constant, the comparative advantage condition need to be adjusted by the curvature of the disutility function. ${ }^{7}$

As for the objective of the government, the prices, and the production side of the economy, we make the same assumptions as in the previous sub-section.

As for designing an income tax system, it is useful to analyze in two steps. The first step is to know how an individual $i$ will choose skilled human capital and unskilled human capital to generate pre-tax income, $R$. The second step is to know, given an after-tax-income schedule of $X=R-T(R)$, how each individual chooses pre-tax income.

The first stage of the problem can be solved considering the following programming problem:

$$
\begin{gathered}
\min f_{s}\left(h_{i}^{s}\right)+f_{u}\left(h_{i}^{u}\right) \\
\text { s.t. } R=w_{i}^{s} \times h_{i}^{s}+w_{i}^{u} \times h_{i}^{u}
\end{gathered}
$$

where $w_{i}^{s}=g_{s i} \times w^{s}$ and $w_{i}^{u}=g_{u i} \times w^{u}$

Let the minimized value of the above problem be $Z\left(w_{i}^{s}, w_{i}^{u}, R\right) . Z\left(w_{i}^{s}, w_{i}^{u}, R\right)$ is the minimized disutility to generate the pre-tax income $R$ for an agent whose net returns from skilled human capital and unskilled capital are $w_{i}^{s}$ and $w_{i}^{u}$, respectively. We denote the solution of the above problem as $h_{i}^{s}\left(w_{i}^{s}, w_{i}^{u}, R\right)$ and $h_{i}^{u}\left(w_{i}^{s}, w_{i}^{u}, R\right)$. For the analysis later, it is useful to calculate compensated human capital supply. Consider the following dual problem of (12):

$$
\begin{aligned}
E\left(w_{i}^{s}, w_{i}^{u}, V\right) & \equiv \max w_{i}^{s} h_{i}^{s}+w_{i}^{u} h_{i}^{u} \\
\text { st. } f_{s}\left(h_{i}^{s}\right)+f_{u}\left(h_{i}^{u}\right) & \leq V
\end{aligned}
$$

\footnotetext{
${ }^{7}$ The economic interpretation of (11) is as follows. Consider a condition that type $i$ and type $i+\varepsilon$ agents have the same degree of comparative advantage. Equation (11) says that if the marginal disutility of accumulating skilled human capital grows faster than the marginal disutility of accumulating unskilled human capital $\left(\gamma_{s}>\gamma_{u}\right)$, then the increase of the return from skilled human capital, $g_{s i}^{\prime} / g_{s i}$, can be lower than the increase of the return from unskilled human capital, $g_{u i}^{\prime} / g_{u i}$, in order to have the same comparative advantage. This is because accumulating skilled human capital accompanies larger disutility from the first place.
} 
Let the solution of the above problem be $\widetilde{h}_{i}^{j}\left(w_{i}^{s}, w_{i}^{u}, V\right)$ where $j=s, u$. Then, from the dual relationship, we will have

$$
h_{i}^{j}\left(w_{i}^{s}, w_{i}^{u}, E\left(w_{i}^{s}, w_{i}^{u}, V\right)\right) \equiv \widetilde{h}_{i}^{j}\left(w_{i}^{s}, w_{i}^{u}, V\right) ; \mathrm{j}=\mathrm{s}, \mathrm{u} .
$$

By taking derivative on both sides, we will have the Slutsky equation for $h_{i}^{s}$ and $h_{i}^{u}$ :

$$
\frac{\partial h_{i}^{j}}{\partial w_{i}^{s}}+\frac{\partial h_{i}^{j}}{\partial R} h_{i}^{s}=\frac{\partial \widetilde{h}_{i}^{j}}{\partial w_{i}^{s}} \text { and } \frac{\partial h_{i}^{j}}{\partial w_{i}^{u}}+\frac{\partial h_{i}^{j}}{\partial R} h_{i}^{u}=\frac{\partial \widetilde{h}_{i}^{j}}{\partial w_{i}^{u}} ; \mathrm{j}=\mathrm{s}, \mathrm{u} .
$$

Note that the indifference curve of $f_{s}\left(h_{i}^{s}\right)+f_{u}\left(h_{i}^{u}\right)$ is strictly concave. Therefore, $\partial \widetilde{h}_{i}^{s} / \partial w_{i}^{s}>0$, $\partial \widetilde{h}_{i}^{u} / \partial w^{u}<0, \partial \widetilde{h}_{i}^{u} / \partial w_{i}^{u}>0$ and $\partial \widetilde{h}_{i}^{u} / \partial w_{i}^{s}<0$. This relationship means that if an individual maximizes his earnings holding the total disutility constant, an increase of the net return from skilled human capital will increase the supply of skilled human capital and an increase of the return of unskilled human capital will decrease the supply for skilled human capital.

Let $X(R)$ be the after-tax income schedule that the government designed. Then, at the second stage of the problem, given $Z\left(w_{i}^{s}, w^{u}, R\right)$ and $X(R)$, each individual $i$ will maximize his utility:

$$
\max _{\{R\}} U\left(p_{1}+t, X(R)\right)-Z\left(w_{i}^{s}, w_{i}^{u}, R\right)
$$

The objective of the social planner is to design a schedule of $X(R)$ to maximize the social welfare. By using the same technique in the previous section, we can calculate $d v / d v i: d v / d i=$ $-\sum_{j=s, u} Z_{w_{i}^{j}} \times\left(d w_{i}^{j} / d i\right)$. Let $\alpha_{i}$ be the Lagrangian multiplier of the required income constraint in the disutility minimization problem (12). From the FOC of the minimization problem for $Z\left(w_{i}^{s}, w_{i}^{u}, R\right)$, we obtain

$$
\frac{d v}{d i}=\alpha_{i} R_{i}\left\{\frac{g_{s i}^{\prime}}{g_{s i}} \theta_{s i}+\frac{g_{u i}^{\prime}}{g_{u i}} \theta_{u i}\right\} \text { where } \theta_{j i}=\frac{w_{i}^{j} h_{i}^{j}}{R_{i}} .
$$

Because of the assumption from the absolute advantage, $d v / d i>0$. (13) has a clear economic meaning. It means that the slope of the value function $v(i)$ is proportional to the weighted average of the absolute advantage of skilled human capital accumulation and unskilled human capital accumulation. For analytical reason, it is useful to eliminate $\alpha_{i}$ in the above equation. 
Using the first order condition for $h_{i}^{s}$ and $h_{i}^{u}$, we can rewrite (13) as follows:

$$
\frac{d v}{d i}=\frac{g_{s i}^{\prime}}{g_{s i}} f_{s}^{\prime}\left(h_{i}^{s}\right) h_{i}^{s}+\frac{g_{u i}^{\prime}}{g_{u i}} f^{\prime}\left(h_{i}^{u}\right) h_{i}^{u}
$$

Given (14), as in the previous section, it is more useful to assume that the social planner controls $v_{i}$ and $R_{i}$ and $x_{i}$ is defined by the following relationship: ${ }^{8}$

$$
v(i)=U\left(p_{1}+t, X_{i}\right)-Z\left(w_{i}^{s}, w_{i}^{u}, R_{i}\right)
$$

The problem of the social planner is to solve the following constrained optimization program:

$$
\begin{gathered}
W(t)=\max _{\left\{R_{i}, v_{i}\right\}} \int_{1}^{2} v(i) n_{i} d i \\
\text { st. } \frac{d v}{d i}=\frac{g_{s i}^{\prime}}{g_{s i}} f_{s}^{\prime}\left(h_{i}^{s}\right) h_{i}^{s}+\frac{g_{u i}^{\prime}}{g_{u i}} f^{\prime}\left(h_{i}^{u}\right) h_{i}^{u} \\
\int_{1}^{2} n_{i}\left\{R_{i}-x_{i}\right\} d i+t \int_{1}^{2} c_{1 i} n_{i} d i=0 \\
H^{s}=\int g_{s i} h_{i}^{s} d i, H^{u}=\int g_{u i} h_{i}^{u} d i, \\
\text { where } p_{1}=p_{1}\left(t, H^{s}, H^{u}\right)
\end{gathered}
$$

and $t$ is given.

In the above programming problem, $W(t)$ is the maximized social welfare for given $t$. Also note that $h_{i}^{s}$ and $h_{i}^{u}$ are functions of $\left(R_{i}, w_{i}^{s}, w_{i}^{u}\right)$ and that $w_{i}^{s}$ and $w_{i}^{u}$ are the functions of $p_{1}$.

After several calculations, we can obtain the following equation (See Appendix):

$$
\left.\frac{d W}{d t}\right|_{t=0}=-\Psi_{2}\left\{\int_{1}^{2} \mu_{i}\left[\gamma^{s}\left(g_{s i}^{\prime} / g_{s i}\right)-\gamma^{u}\left(g_{u i}^{\prime} / g_{u i}\right)\right] f_{s}^{i}\left[\frac{\partial \widetilde{h}_{i}^{s}}{\partial w_{i}^{s}} \frac{d w_{i}^{s}}{d p_{1}}+f_{s}^{\prime} \frac{\partial \widetilde{h}_{i}^{s}}{\partial w_{i}^{u}} \frac{d w_{i}^{u}}{d p_{1}}\right] d i\right\}
$$

where

$$
\Psi_{2}=\frac{R D_{p}}{R S_{p}-R D_{p}+R S_{H^{s}} \int_{1}^{2} g_{i}^{s}\left[\frac{\partial \widetilde{h}_{i}^{s}}{\partial w_{i}^{s}} \frac{d w_{i}^{s}}{d p_{1}}+\frac{\partial \widetilde{h}_{i}^{s}}{\partial w_{i}^{u}} \frac{d w_{i}^{u}}{d p_{1}}\right] d i+R S_{H^{u}} \int_{1}^{2} g_{i}^{u}\left[\frac{\partial \widetilde{h}_{i}^{u}}{\partial w_{i}^{s}} \frac{d w_{i}^{s}}{d p_{1}}+\frac{\partial \widetilde{h}_{i}^{u}}{\partial w_{i}^{u}} \frac{d w_{i}^{u}}{d p_{1}}\right] d i}
$$

and $\mu_{i}$ is the Lagrangian multiplier of the incentive compatibility constraint. Because of the property of the compensated supply function of $h_{i}^{s}, \partial \widetilde{h}_{i}^{s} / \partial w_{i}^{s}>0$ and $\partial \widetilde{h}_{i}^{s} / \partial w_{i}^{u}<0$. From the

\footnotetext{
${ }^{8}$ As for SCP, we can check it by examining $\frac{\partial^{2} Z}{\partial R \partial i}>0$. This is true as long as $\frac{\partial h_{i}^{j}}{\partial R}>0$ for $\mathrm{j}=\mathrm{s}, \mathrm{u}$.
} 
Stolper-Samuelson theorem, $\partial w_{i}^{s} / \partial p_{1}>0$ and $\partial w_{i}^{u} / \partial p_{1}<0$. From the Rybcyzynski theorem, $R S_{H^{s}}>0$ and $R S_{H^{u}}<0$. From the assumption on comparative advantage, $\gamma_{s}\left(g_{s i}^{\prime} / g_{s i}\right)-$ $\gamma_{u}\left(g_{u i}^{\prime} / g_{u i}\right)>0$. As for the sign of the Lagrangian multiplier of the incentive compatibility constraint, the standard argument shows that $\mu_{i}>0$ for all $i \in(1,2)$ (See Appendix). Thus, we obtain $d W / d t>0$.

Proposition 2 Suppose that the social planner sets the income tax structure to maximize the social welfare function in an endogenous skill accumulation model at the zero commodity tax . Then an introduction of a commodity tax on an skilled-labor-intensive good will increase the social welfare.

Equation (15) has several implications. For an illustration, consider a situation where the disutility functions of skilled and unskilled human capital accumulation have the same degree of curvature, i.e. $\gamma_{s}=\gamma_{u} \equiv \gamma$. Then, (15) shows that if $\left(g_{s i}^{\prime} / g_{s i}\right)=\left(g_{u i}^{\prime} / g_{u i}\right), d W / d t=0$. In other words, if there is no comparative advantage and if higher ability individuals are as good at accumulating skilled and unskilled human capital as lower ability individuals, then there is no welfare gain from changing the returns of skilled and unskilled human capital. Second, $\left(\partial \widetilde{h}_{i}^{s} / \partial w_{i}^{s}\right)\left(\partial w_{i}^{s} / \partial p_{1}\right)$ and $\left(\partial \widetilde{h}_{i}^{s} / \partial w_{i}^{u}\right)\left(\partial w_{i}^{u} / \partial p_{1}\right)$ measure how changes of returns from each types of human capital changes the compensated supply of skilled human capital. Third, $\Psi_{2}$ measure how a change of the commodity tax $t$ will change the relative price of good 1 taking into the effect of changes of the supply of human capital into consideration. ${ }^{9}$ Also note that $\gamma \times f_{s}^{\prime}\left(h_{i}^{s}\right)=$ $f_{s}^{\prime \prime}\left(h_{i}^{s}\right) h_{i}^{s}+f_{s}^{\prime}\left(h_{i}^{s}\right)$ and that $f_{s}^{\prime \prime}\left(h_{i}^{s}\right) h_{i}^{s}+f_{s}^{\prime}\left(h_{i}^{s}\right)$ is related with a change of $\dot{v}$. In addition, note that $\mu_{i}$ measures how the social welfare increases when the incentive compatibility is relaxed. This implies that the term after the integration measures how a compensated change of the returns from skilled and unskilled human capital changes the slope of $\dot{v}$ and increases the social welfare.

\footnotetext{
${ }^{9}$ First note that the total skilled and unskilled human capital are functions of the price of good1. Thus, for a given level of the commodity tax, the equilibrium price can be determined from

$R S\left(t+p_{1}\right)=R S\left(p_{1}, H^{s}\left(p_{1}\right), H^{u}\left(p_{1}\right)\right)$. Second, $\int_{1}^{2} g_{i}^{s}\left[\frac{\partial \widetilde{h}_{i}^{s}}{\partial w_{i}^{s}} \frac{\partial w_{i}^{s}}{\partial p_{1}}+\frac{\partial \widetilde{h}_{i}^{s}}{\partial w_{i}^{u}} \frac{\partial w_{i}^{u}}{\partial p_{1}}\right] d i$ and $\int_{1}^{2} g_{i}^{u}\left[\frac{\partial \widetilde{h}_{i}^{u}}{\partial w_{i}^{s}} \frac{\partial w_{i}^{s}}{\partial p_{1}}+\frac{\partial \widetilde{h}_{i}^{u}}{\partial w_{i}^{u}} \frac{\partial w_{i}^{u}}{\partial p_{1}}\right] d i$ are the compensated change of supply of skilled and unskilled human capital when the price of good 1 increases. Thus, we obtain $d p_{1} / d t=\Psi_{2}$
} 
The intuition of the above proposition is as follows. In a situation where higher ability individuals have comparative advantage in accumulating skilled human capital and lower ability individuals have comparative advantage in accumulating unskilled human capital, a decrease of the return from skilled human capital and an increase of the return from unskilled human capital will hurt higher ability individuals and benefit lower ability individuals. If the social planner is interested in redistributing income from high ability individuals to low ability individuals, such changes of the returns from skilled and unskilled capital can indirectly redistribute income. On the other hand, starting from zero distortion, the deadweight loss of the commodity tax is of the second-order but the welfare gain of relaxing the incentive problem has the first-order effect. As a result, introducing the production distortion increases the social welfare.

\section{Conclusion}

In this paper, we have examined whether using a commodity tax can increase the social welfare in the presence of a nonlinear income tax system when human capital accumulation is endogenous. For that purpose, I developed two models where individuals can choose the amount of both skilled and unskilled human capital based on their comparative advantage. In the first model, we assumed that skilled human capital and unskilled human capital are perfect substitutes and that individuals accumulate only skilled or unskilled human capital. In the second model, we assumed that skilled human capital and unskilled human capital are imperfect substitutes and that individuals accumulate both types of human capital. Assuming that individuals with higher ability have comparative advantage in accumulating skilled human capital, we have shown that indirect redistribution such imposing a tariff on unskilled human capital intensive good can increase the efficiency and complement an income tax system. This suggests that validity of the Atkinson and Stiglitz theorem depends on how the process of human capital accumulation is modelled. The result of this paper also suggests that empirical studies such as Dinardo and Tobias (2001) and Tobias (2003) that showed the returns from human capital were different among 
individuals with different abilities have important implications for public policy. For example, as Dinardo and Tobias (2001) and Tobias (2003) have shown, if the return from college education is higher for people with higher ability, the subsidy to college education can have negative effect on social welfare.

\section{Appendix}

\section{Proof of Proposition 1}

The Lagrangian is:

$$
\begin{gathered}
L=\int_{1}^{i^{*}} v^{u}(i) n_{i} d i+\int_{i^{*}}^{2} v^{s}(i) n_{i} d i+\int_{1}^{i^{*}} \mu_{i}^{u}\left\{v^{u}-a^{u} h_{i}^{u}\left(g_{u i}^{\prime} / g_{u i}\right)\right\} d i+\int_{i^{*}}^{2} \mu_{i}^{s}\left\{v^{s}-a^{s} h_{i}^{s}\left(g_{s i}^{\prime} / g_{s i}\right)\right\} d i \\
+\beta_{1}\left\{v_{i^{*}}^{s}-v_{i^{*}}^{u}\right\}+\beta_{2}\left\{R_{i^{*}}^{s}-R_{i^{*}}^{u}\right\} \\
+\lambda \int_{1}^{i^{*}}\left\{R_{i}^{u}-x\left(R_{i}^{u}, v_{i}^{u}, w_{i}^{s}, w_{i}^{u}, p_{1}+t\right)\right\} n_{i} d i+\lambda \int_{i^{*}}^{2}\left\{R_{i}^{s}-x\left(R_{i}^{s}, v_{i}^{s}, w_{i}^{s}, w_{i}^{u}, p_{1}+t\right)\right\} n_{i} d i \\
+\lambda t \int_{1}^{2} n_{i} c_{1 i} d i+\beta_{s}\left\{\int_{i^{*}}^{2} g_{s i} h_{i}^{s} d i-H^{s}\right\}+\beta_{u}\left\{\int_{1}^{i^{*}} g_{u i} h_{i}^{u} d i-H^{u}\right\}
\end{gathered}
$$

Denote $x\left(R_{i}^{j}, v_{i}^{j}, w_{i}^{s}, w_{i}^{u}, p_{1}+t\right)$ as $x^{i}$ where $j=s, u$. By using the integration by parts, we obtain

$$
\begin{gathered}
L=\int_{1}^{i^{*}} v^{u}(i) n_{i} d i+\int_{i^{*}}^{2} v^{s}(i) n_{i} d i+\mu_{i^{*}}^{u} v_{i^{*}}^{u}-\mu_{1}^{u} v_{1}^{u}-\int_{1}^{i *} \mu_{i}^{u} v_{i}^{u} d i-\int_{1}^{i^{*}} \mu_{i}^{u} a^{u} h_{i}^{u}\left(g_{u i}^{\prime} / g_{u i}\right) d i \\
\mu_{2}^{s} v_{2}^{s}-\mu_{i^{*}}^{s} v_{i^{*}}^{s}-\int_{i^{*}}^{2} \mu_{i}^{s} v_{i}^{s} d i-\int_{i^{*}}^{2} \mu_{i}^{s} a^{s} h_{i}^{s}\left(g_{s i}^{\prime} / g_{s i}\right) d i+\beta_{1}\left\{v_{i^{*}}^{s}-v_{i^{*}}^{u}\right\}+\beta_{2}\left\{R_{i^{*}}^{s}-R_{i^{*}}^{u}\right\} \\
+\lambda \int_{1}^{i^{*}}\left\{R_{i}^{u}-x\left(R_{i}^{u}, v_{i}^{u}, q, w_{i}^{s}, w_{i}^{u}, p_{1}+t\right)\right\} n_{i} d i+\lambda \int_{i^{*}}^{2}\left\{R_{i}^{s}-x\left(R_{i}^{s}, v_{i}^{s}, w_{i}^{s}, w_{i}^{u}, p_{1}+t\right)\right\} n_{i} d i \\
+\lambda t \int_{1}^{2} n_{i} c_{1 i} d i++\beta_{s}\left\{\int_{i^{*}}^{2} g_{s i} h_{i}^{s} d i-H^{s}\right\}+\beta_{u}\left\{\int_{1}^{i^{*}} g_{u i} h_{i}^{u} d i-H^{u}\right\}
\end{gathered}
$$

Denote $x\left(R_{i}^{j}, v_{i}^{j}, w_{i}^{s}, w_{i}^{j}, p_{1}+t\right)$ as $x^{i}$ where $j=s, u$. The first order condition for $v_{i}^{s}, v_{2}^{s}, v_{i^{*}}^{s}, R_{i}^{s}$, $R_{i^{*}}^{s}, v_{i}^{u}, v_{i^{*}}^{u}, v_{1}^{u}, R_{i}^{u}, R_{i^{*}}^{u}, H^{s}$ and $H^{u}$ are

$$
\begin{gathered}
v_{i}^{s}: n_{i}-\dot{\mu}_{i}^{s}-\lambda n_{i} \frac{\partial x_{i}}{\partial v_{i}^{s}}+\lambda t n_{i} \frac{\partial c_{1 i}}{\partial x_{i}} \frac{\partial x_{i}}{\partial v_{i}^{s}}=0 \\
v_{2}^{s}: \mu_{2}^{s}=0 \\
v_{i^{*}}^{s}:-\mu_{i^{*}}^{s}+\beta_{1}=0
\end{gathered}
$$




$$
\begin{gathered}
R_{i}^{s}:\left[-\mu_{i}^{s} \times a^{s} \frac{g_{s i}^{\prime}}{g_{s i}}+\beta_{s} g_{s i}\right] \frac{\partial h_{i}^{s}}{\partial R_{i}^{s}}+\lambda n_{i}-\lambda n_{i} \frac{\partial x_{i}}{\partial R_{i}^{s}}+\lambda t n_{i} \frac{\partial c_{1 i}}{\partial x_{i}} \frac{\partial x_{i}}{\partial R_{i}}=0 \\
R_{i^{*}}^{s}: \beta_{2}=0 \\
v_{i}^{u}: n_{i}-\dot{\mu}_{i}^{s}-\lambda n_{i} \frac{\partial x_{i}}{\partial v_{i}^{s}}+\lambda t n_{i} \frac{\partial c_{1 i}}{\partial x_{i}} \frac{\partial x_{i}}{\partial v_{i}^{s}}=0 \\
v_{i^{*}}^{u}: \mu_{i^{*}}^{u}-\beta_{1}=0 \\
R_{i}^{u}:\left[-\mu_{i}^{u} \times a^{u} \frac{g_{u i}^{\prime}}{g_{u i}}+\mu_{u}^{u}=0\right. \\
\left.R_{u i}\right] \frac{\partial h_{i}^{u}}{\partial R_{i}^{u}}+\lambda n_{i}-\lambda n_{i} \frac{\partial x_{i}}{\partial R_{i}^{u}}+\lambda t n_{i} \frac{\partial c_{1 i}}{\partial x_{i}} \frac{\partial x_{i}}{\partial R_{i}^{u}}=0 \\
H^{s}: \frac{\partial L}{\partial p_{1}} \frac{\partial p_{1}}{\partial H^{s}}=\beta_{s} \\
H^{u}: \frac{\partial L}{\partial p_{1}} \frac{\partial p_{1}}{\partial H^{u}}=\beta_{u}
\end{gathered}
$$

Now we characterize those first order conditions. First, note that

$$
\mu_{i}^{s}=\mu_{i^{*}}^{s}+\int_{1}^{i^{*}} n_{j}\left(1-\lambda \frac{\partial x_{j}}{\partial v_{j}}\right) d j \text { and } \mu_{i^{*}}^{u}=\mu_{1}^{u}+\int_{1}^{i^{*}} n_{j}\left(1-\lambda \frac{\partial x_{j}}{\partial v_{j}}\right) d j
$$

Since $\mu_{i^{*}}^{s}=\mu_{i^{*}}^{u}, \mu_{i}^{s}=\int_{1}^{i} n_{j}\left(1-\lambda \frac{\partial x_{j}}{\partial v_{j}}\right) d j \quad$ for $i \in\left(i^{*}, 2\right)$ and $\mu_{i}^{u}=\int_{1}^{i} n_{j}\left(1-\lambda \frac{\partial x_{j}}{\partial v_{j}}\right) d j$ for $i \in\left(1, i^{*}\right)$ Note that $\frac{\partial x_{j}}{\partial v_{j}}=1 /\left(U_{x}\right)$. A single crossing property and the monotonicity of $R_{i}^{s}$ and $R_{i}^{u}$ guarantee that $x_{i}$ is increasing. This implies that $\frac{\partial x_{j}}{\partial v_{j}}$ is increasing and the inside of the integral is a decreasing function of $i$. Since $\mu_{2}^{s}=0$ and $\mu_{1}^{u}=0$, the only way that those conditions are satisfied is that initially $n_{i}\left(1-\lambda \frac{\partial x_{j}}{\partial v_{j}}\right)$ is positive and after some $i^{* *}$, it becomes negative. In this case, for all $i_{s} \in\left[i^{*}, 2\right)$ and $i_{u} \in\left(1, i^{*}\right], \mu_{i_{s}}^{s}$ and $\mu_{i_{s}}^{u}$ are strictly positive.

Now we examine $d W / d t$ and evaluate at $t=0$. From the envelope theorem,

$$
\frac{d W}{d t}=\frac{\partial L}{\partial p_{1}} \frac{\partial p_{1}}{\partial t}+\lambda \int_{1}^{2} n_{i} c_{1 i} d i-\lambda \int_{i^{*}}^{2} \frac{\partial x_{i}}{\partial\left(p_{1}+t\right)} n_{i} d i-\lambda \int_{1}^{i^{*}} \frac{\partial x_{i}}{\partial\left(p_{1}+t\right)} n_{i} d i
$$


where

$$
\begin{gathered}
\frac{\partial L}{\partial p_{1}}=\frac{d i^{*}}{d p}\left\{v_{i^{*}}^{u} n_{i^{*}}-v_{i^{*}}^{s} n_{i^{*}}+\mu_{i^{*}}^{u} v_{i^{*}}^{u}+\mu_{i^{*}}^{u} v_{i^{*}}^{u}-\mu_{i^{*}}^{u} v_{i *}^{u}-\mu_{i^{*}}^{u} a^{u} h_{i^{*}}^{u} \frac{g_{u i^{*}}^{\prime}}{g_{u i^{*}}}\right. \\
-\dot{\mu}_{i^{*}}^{s} v_{i^{*}}^{s}-\mu_{i^{*}}^{s} \dot{v}_{i^{*}}^{s}+\dot{\mu}_{i^{*}}^{s} v\left(i^{*}\right)+\mu_{i^{*}}^{s} a^{s} h_{i^{*}}^{s} \frac{g_{i^{*}}^{\prime}}{g_{s i^{*}}}+\beta_{1}\left\{\dot{v}_{i^{*}}-\dot{v}_{i^{*}}^{u}\right\}+\beta_{2} \dot{R}_{i^{*}}^{u}-\beta_{2} \dot{R}_{i^{*}} \\
-\lambda\left\{R_{i^{*}}^{s}-x\left(R_{i^{*}}^{s}, v_{i^{*}}^{s}, p_{1}+t, w_{i^{*}}^{s}, w_{i^{*}}^{u}\right)\right\} n_{i^{*}}+\lambda\left\{R_{i^{*}}^{u}-x\left(R_{i^{*}}^{u}, v_{i^{*}}^{u}, p_{1}+t, w_{i^{*}}^{s}, w_{i^{*}}^{u}\right)\right\} n_{i^{*}} \\
\left.-\beta_{u} g_{u i^{*}} h_{i^{*}}\right\} \\
+\left\{\int_{i^{*}}^{2}\left[-\mu_{i}^{s} a^{s}\left(g_{s i}^{\prime} / g_{s i}\right)+\beta_{s} g_{s i}\right] \frac{\partial h_{i}^{s}}{\partial w_{i}^{s}} \frac{\partial w_{i}^{s}}{\partial p_{1}} d i-\lambda \int_{i^{*}}^{2} \frac{\partial x_{i}}{\partial w_{i}^{s}} \frac{\partial w_{i}^{s}}{\partial p_{1}} n_{i} d i\right\} \\
+\left\{\int_{i^{*}}^{2}\left[-\mu_{i}^{u} a^{u}\left(g_{u i}^{\prime} / g_{u i}\right)+\beta_{u} g_{u i}\right] \frac{\partial h_{i}^{u}}{\partial w_{i}^{u}} \frac{\partial w_{i}^{u}}{\partial p_{1}}-\lambda \int_{1}^{i^{*}} \frac{\partial x_{i}}{\partial w_{i}^{u}} \frac{\partial w_{i}^{u}}{\partial p_{1}} n_{i} d i\right\} \\
-\lambda \int_{i^{*}}^{2} \frac{\partial x_{i}}{\partial\left(p_{1}+t\right)} n_{i} d i-\lambda \int_{1}^{i^{*}} \frac{\partial x_{i}}{\partial\left(p_{1}+t\right)} n_{i} d i
\end{gathered}
$$

By using the above first order conditions, we have

$$
\begin{aligned}
\frac{\partial L}{\partial p_{1}} & =\frac{d i^{*}}{d p_{1}}\left\{\mu_{i^{*}}^{s} a^{s} h_{i}^{s} \frac{g_{s}^{\prime}}{g_{s}}-\mu_{i^{*}}^{u} a^{u} h_{i}^{u} \frac{g_{u}^{\prime}}{g_{u}}-\beta_{s} g_{s i^{*}} h_{i^{*}}^{s}+\beta_{s} g_{s i^{*}} h_{i^{*}}^{s}\right\} \\
& +\left\{\int_{i^{*}}^{2}\left[-\mu_{i}^{s} a^{s}\left(g_{s i}^{\prime} / g_{s i}\right)+\beta_{s} g_{s i}\right] \frac{\partial h_{i}^{s}}{\partial w_{i}^{s}} \frac{\partial w_{i}^{s}}{\partial p_{1}} d i-\lambda \int_{i^{*}}^{2} \frac{\partial x_{i}}{\partial w_{i}^{s}} \frac{\partial w_{i}^{s}}{\partial p_{1}} n_{i} d i\right\} \\
& +\left\{\int_{i^{*}}^{2}\left[-\mu_{i}^{u} a^{u}\left(g_{u i}^{\prime} / g_{u i}\right)+\beta_{u} g_{u i}\right] \frac{\partial h_{i}^{u}}{\partial w_{i}^{u}} \frac{\partial w_{i}^{u}}{\partial p_{1}}-\lambda \int_{1}^{i^{*}} \frac{\partial x_{i}}{\partial w_{i}^{u}} \frac{\partial w_{i}^{u}}{\partial p_{1}} n_{i} d i\right\} \\
& -\lambda \int_{i^{*}}^{2} \frac{\partial x_{i}}{\partial\left(p_{1}+t\right)} n_{i} d i-\lambda \int_{1}^{i^{*}} \frac{\partial x_{i}}{\partial\left(p_{1}+t\right)} n_{i} d i
\end{aligned}
$$

Now we need to calculate the inside of the integral. Note that from the definition of $h_{i}^{s}$ and $h_{i}^{u}$, we have

$$
\frac{\partial h_{i}^{s}}{\partial w_{i}^{s}}=-h_{i}^{s} \frac{\partial h_{i}^{s}}{\partial R_{i}^{s}} \text { and } \frac{\partial h_{i}^{u}}{\partial w_{i}^{u}}=-h_{i}^{u} \frac{\partial h_{i}^{u}}{\partial R_{i}^{u}}
$$

This implies that

$$
\begin{array}{r}
{\left[-\mu_{i}^{s} a^{s}\left(g_{s i}^{\prime} / g_{s i}\right)+\beta_{s} g_{s i}\right] \frac{\partial h_{i}^{s}}{\partial w_{i}^{s}}=\left[\mu_{i}^{s} a^{s s}\left(g_{s i}^{\prime} / g_{s i}\right)-\beta_{s} g_{s i}\right] h_{i}^{s} \frac{\partial h_{i}^{s}}{\partial R_{i}^{s}}} \\
\text { and }\left[-\mu_{i}^{u} a^{u}\left(g_{u i}^{\prime} / g_{u i}\right)+\beta_{u} g_{u i}\right] \frac{\partial h_{i}^{u}}{\partial w_{i}^{u}}=\left[\mu_{i}^{u} a^{u}\left(g_{u i}^{\prime} / g_{u i}\right)-\beta_{u} g_{u i}\right] h_{i}^{u} \frac{\partial h_{i}^{u}}{\partial R_{i}^{u}}
\end{array}
$$


By using the FOC of $R_{i}^{s}$ and $R_{i}^{u}$,

$$
\begin{gathered}
{\left[\mu_{i}^{s} a^{s s}\left(g_{s i}^{\prime} / g_{s i}\right)-\beta_{s} g_{s i}\right] h_{i}^{s} \frac{\partial h_{i}^{s}}{\partial R_{i}^{s}}=h_{i}^{s}\left\{\lambda n_{i}-\lambda n_{i} \frac{\partial x}{\partial R_{i}^{s}}\right\}} \\
{\left[\mu_{i}^{s} a^{s s}\left(g_{s i}^{\prime} / g_{s i}\right)-\beta_{u} g_{s i}\right] h_{i}^{u} \frac{\partial h_{i}^{u}}{\partial R_{i}^{u}}=h_{i}^{u}\left\{\lambda n_{i}-\lambda n_{i} \frac{\partial x}{\partial R_{i}^{u}}\right\}}
\end{gathered}
$$

Thus, $\frac{\partial L}{\partial p_{1}}$ is

$$
\begin{aligned}
\frac{\partial L}{\partial p_{1}} & =\frac{d i^{*}}{d t}\left\{\mu_{i^{*}}^{s} a^{s} h_{i}^{s} \frac{g_{s i^{*}}^{\prime}}{g_{s i^{*}}}-\mu_{i^{*}}^{u} a^{u} h_{i}^{u} \frac{g_{u i^{*}}^{\prime}}{g_{u i^{*}}}-\beta_{s} g_{s i^{*}} h_{i^{*}}^{s}+\beta_{u} g_{u i^{*}} h_{i^{*}}^{u}\right\} \\
& +\left\{\int_{i^{*}}^{2} h_{i}^{s}\left\{\lambda n_{i}-\lambda n_{i} \frac{\partial x_{i}}{\partial R_{i}^{s}}\right\} \frac{\partial w_{i}^{s}}{\partial p_{1}} d i-\lambda \int_{i^{*}}^{2} \frac{\partial x_{i}}{\partial w_{i}^{s}} \frac{\partial w_{i}^{s}}{\partial p_{1}} n_{i} d i\right\} \\
& +\left\{\int_{i^{*}}^{2} h_{i}^{u}\left\{\lambda n_{i}-\lambda n_{i} \frac{\partial x_{i}}{\partial R_{i}^{u}}\right\} \frac{\partial w_{i}^{u}}{\partial p_{1}} d i-\lambda \int_{1}^{i^{*}} \frac{\partial x_{i}}{\partial w_{i}^{u}} \frac{\partial w_{i}^{u}}{\partial p_{1}} n_{i} d i\right\} \\
& -\lambda \int_{i^{*}}^{2} \frac{\partial x_{i}}{\partial\left(p_{1}+t\right)} n_{i} d i-\lambda \int_{1}^{i^{*}} \frac{\partial x_{i}}{\partial\left(p_{1}+t\right)} n_{i} d i
\end{aligned}
$$

Next, we need to calculate $\lambda \int_{i^{*}}^{2} h_{i}^{s} n_{i} \frac{\partial w_{i}^{s}}{\partial p_{1}}+\lambda \int_{1}^{i^{*}} h_{i}^{u} n_{i} \frac{\partial w_{i}^{u}}{\partial p_{1}} d i$. Note that $\lambda \int_{i^{*}}^{2} h_{i}^{s} n_{i} \frac{\partial w_{i}^{s}}{\partial p_{1}}+\lambda \int_{1}^{i^{*}} h_{i}^{u} n_{i} \frac{\partial w_{i}^{u}}{\partial p_{1}} d i=$ $\lambda \int_{i^{*}}^{2} h_{i}^{s} g_{s i i} \frac{\partial w^{s}}{\partial p_{1}}+\lambda \int_{1}^{i^{*}} h_{i}^{u} g_{u i} n_{i} \frac{\partial w^{u}}{\partial p_{1}} d i . \quad \lambda \int_{i^{*}}^{2} h_{i}^{s} g_{s i i} \frac{\partial w^{s}}{\partial p_{1}}+\lambda \int_{1}^{i^{*}} h_{i}^{u} g_{u i} n_{i} \frac{\partial w^{u}}{\partial p_{1}} d i$ is a change of total earning due to a change of the price of good 1 when levels of human capital of all individuals are fixed. On the other hand, from perfect competition, for given level of human capital of all individuals, the total revenue of the firm should be equal to the total payment to factor owners. Thus, $p_{1} y_{1}+y_{2}=w^{s} \int_{i^{*}}^{2} n_{i} h_{i}^{s} g_{s i} d i+w^{u} \int_{1}^{i^{*}} n_{i} h_{i}^{u} g_{u i} d i$ always holds. Let $Q\left(p_{1}\right)$ be the total revenue of firms when all human capital level of all individuals are fixed. Then, $d Q / d p_{1}=\lambda \int_{i^{*}}^{2} h_{i}^{s} g_{s i i} \frac{\partial w^{s}}{\partial p_{1}}+\lambda \int_{1}^{i^{*}} h_{i}^{u} g_{u i} n_{i} \frac{\partial w^{u}}{\partial p_{1}} d i$. By definition of $Q\left(p_{1}\right)$

$$
\begin{aligned}
& Q\left(p_{1}\right) \equiv \max p_{1} y_{1}+y_{2} \quad \text { s.t. }\left(y_{1}, y_{2}\right) \in \Gamma\left(H^{s}, H^{u}\right) \\
& H^{s} \text { and } H^{u} \text { are fixed. }
\end{aligned}
$$

From the envelope theorem, $\frac{d Q}{d p_{1}}=y_{1}$. Therefore, we have

$$
\lambda y_{1}=\lambda \frac{\partial w^{s}}{\partial \sigma} \int_{i^{*}}^{2} h_{i}^{s} g_{s i} n_{i}+\lambda \frac{\partial w^{u}}{\partial \sigma} \int_{1}^{i^{*}} h_{i}^{u} g_{u i} n_{i} d i .
$$

Third, we will show that $h_{i}^{s} \frac{\partial x}{\partial R_{i}^{s}}=-\frac{\partial x}{\partial w_{i}^{s}}$ and $h_{i}^{u} \frac{\partial x}{\partial R_{i}^{u}}=-\frac{\partial x}{\partial w_{i}^{u}}$. From the definition of $Z$, we 
have

$$
\begin{aligned}
& \frac{\partial Z}{\partial R_{i}^{s}}=a^{s} / w_{i}^{s} \text { and } \frac{\partial Z}{\partial w_{i}^{s}}=-a^{s} h_{i}^{s}\left(1 / w_{i}^{s}\right) \text { for } i \in\left(i^{*}, 2\right) \\
& \frac{\partial Z}{\partial R_{i}^{u}}=a^{u} / w_{i}^{u} \text { and } \frac{\partial Z}{\partial w_{i}^{u}}=-a^{u} h_{i}^{u}\left(1 / w_{i}^{s}\right) \text { for } i \in\left(1, i^{*}\right)
\end{aligned}
$$

Thus, by using the definition of $\frac{\partial x}{\partial R_{i}^{s}}, \frac{\partial x}{\partial w^{s}}, \frac{\partial x}{\partial R_{i}^{s}}, \frac{\partial x}{\partial w^{s}}$, we can check that $h_{i}^{s} \frac{\partial x}{\partial R_{i}^{s}}=-\frac{\partial x}{\partial w_{i}^{s}}$ and $h_{i}^{u} \frac{\partial x}{\partial R_{i}^{u}}=$ $-\frac{\partial x}{\partial w_{i}^{u}}$.

Therefore, $d L / d p_{1}$ is

$$
\left.\frac{\partial L}{\partial p_{1}}\right|_{\sigma=0}=\frac{d i^{*}}{d p_{1}}\left\{\mu_{i^{*}}^{s} a^{s} h_{i^{*}}^{s} \frac{g_{s}^{\prime}}{g_{s}}-\mu_{i^{*}}^{u} a^{u} h_{i^{*}}^{u} \frac{g_{u}^{\prime}}{g_{u}}-\frac{\partial L}{\partial p_{1}} \frac{\partial p_{1}}{\partial H^{s}} g_{s i^{*}} h_{i^{*}}^{s}+\frac{\partial L}{\partial p_{1}} \frac{\partial p_{1}}{\partial H^{u}} g_{u i^{*}} h_{i^{*}}^{u}\right\}
$$

From the FOC of $H^{s}$ and $H^{u}$, we have

$$
\frac{\partial L}{\partial p_{1}}\left\{1+\frac{d i^{*}}{d p_{1}}\left[\frac{\partial p_{1}}{\partial H^{s}} g_{s i^{*}} h_{i^{*}}^{s}-\frac{\partial p_{1}}{\partial H^{u}} g_{u i^{*}} h_{i^{*}}^{u}\right]\right\}=\frac{d i^{*}}{d p_{1}}\left\{\mu_{i^{*}}^{s} a^{s} h_{i^{*}}^{s} \frac{g_{s}^{\prime}}{g_{s}}-\mu_{i^{*}}^{u} a^{u} h_{i^{*}}^{u} \frac{g_{u}^{\prime}}{g_{u}}\right\}
$$

Therefore, this implies that

$$
\frac{\partial L}{\partial p_{1}}=\frac{\frac{d i^{*}}{d p_{1}}}{\triangle^{\prime}}\left\{\mu_{i^{*}}^{s} a^{s} h_{i^{*}}^{s} \frac{g_{s}^{\prime}}{g_{s}}-\mu_{i^{*}}^{u} a^{u} h_{i^{*}}^{u} \frac{g_{u}^{\prime}}{g_{u}}\right\}
$$

where $\triangle^{\prime}=1+\frac{d i^{*}}{d p_{1}}\left[\frac{\partial p_{1}}{\partial H^{s}} g_{s i^{*}} h_{i^{*}}^{s}-\frac{\partial p_{1}}{\partial H^{u}} g_{u i^{*}} h_{i^{*}}^{u}\right]>0$. By using the definition of $\partial p_{1} / \partial t, \partial p_{1} / \partial H^{s}$ and $\partial p_{1} / \partial H$, we have

$$
\left.\frac{d W}{d t}\right|_{t=0}=\Psi_{1} \frac{d i^{*}}{d p_{1}}\left\{\mu_{i^{*}}^{s} a^{s} h_{i^{*}}^{s} \frac{g_{s}^{\prime}}{g_{s}}-\mu_{i^{*}}^{u} a^{u} h_{i^{*}}^{u} \frac{g_{u}^{\prime}}{g_{u}}\right\}
$$

where

$$
\text { where } \Psi_{1}=\frac{-R D_{p}}{R D_{p}-R S_{p}+R S_{H^{s}} \frac{\partial i^{*}}{\partial p_{1}} g_{s i^{*}} h_{i^{*}}^{s}-R S_{H^{u}} \frac{\partial i^{*}}{\partial p_{1}} g_{u i^{*}} h_{i^{*}}^{u}}
$$

From the FOC of $v_{i^{*}}^{s}$ and $v_{i^{*}}^{u}$, we have $\mu_{i^{*}}^{s}=\mu_{i^{*}}^{u}$. In addition, $a^{s} h_{i}^{s} \frac{g_{s}^{\prime}}{g_{s}}$ and $a^{u} h_{i}^{u} \frac{g_{u}^{\prime}}{g_{u}}$ are the right side slope of $v_{i}^{s}$ and the left side slope $v_{i}^{u}$ at $i^{*}$ From Lemma 1, the slope of $v_{i}^{s}$ is steeper than the slope of $v_{i}^{u}$ at $i^{*}$. Since $\frac{d i^{*}}{d p_{1}}<0, \frac{d W}{d t}>0$. 


\section{Proof of the Proposition 2}

Let $\mu_{i}$ and $\lambda$ be the Lagrangian multiplier of the incentive constraint and the resource constraint.

Denote $x\left(R_{i}^{j}, v_{i}, w_{i}^{s}, w_{i}^{u}, p_{1}+t\right)$ as $x^{i}$. Then, the Lagrangian function is

$$
\begin{gathered}
W(t)=\int_{1}^{2} v_{i} n_{i} d i+\int_{1}^{2} \mu_{i}\left[\frac{d v}{d i}-f_{s}^{\prime}\left(h_{i}^{s}\right) h_{i}^{s}\left(g_{s i}^{\prime} / g_{s i}\right)-f_{u}^{\prime}\left(h_{i}^{u}\right) h_{i}^{u}\left(g_{u i}^{\prime} / g_{u i}\right) d i\right]+ \\
+\lambda \int_{1}^{2} n_{i}\left\{R_{i}-x_{i}\right\} d i+t \int_{1}^{2} n_{i} c_{1 i} d i \\
+\beta_{s}\left\{\int_{1}^{2} g_{s i} h_{i}^{s} d i-H^{s}\right\}+\beta_{u}\left\{\int_{1}^{2} g_{u i} h_{i}^{u} d i-H^{u}\right\}
\end{gathered}
$$

By using the integration by parts, we can obtain

$$
\begin{aligned}
W(t) & =\int_{1}^{2} v_{i} n_{i} d i+\int_{1}^{2} \mu_{i} \frac{d v}{d i} d i-\int_{1}^{2} \mu_{i} f_{s}^{\prime}\left(h_{i}^{s}\right) h_{i}^{s}\left(g_{s i}^{\prime} / g_{s i}\right) d i-\int_{1}^{2} \mu_{i} f_{u}^{\prime}\left(h_{i}^{u}\right) h_{i}^{u}\left(g_{u i}^{\prime} / g_{u i}\right) d i \\
& +\lambda \int_{1}^{2} n_{i}\left\{R_{i}-x_{i}\right\} d i+\lambda t \int_{1}^{2} n_{i} c_{1 i} d i+\beta_{s}\left\{\int_{1}^{2} g_{s i} h_{i}^{s} d i-H^{s}\right\}+\beta_{u}\left\{\int_{1}^{2} g_{u i} h_{i}^{u} d i-H^{u}\right\} \\
& =\int_{1}^{2} v_{i} n_{i} d i+\mu_{2} v_{2}-\mu_{1} v_{1}-\int_{1}^{2} \dot{u}_{i} v_{i} d i-\int_{1}^{2} \mu_{i} f_{s}^{\prime}\left(h_{i}^{s}\right) h_{i}^{s}\left(g_{s i}^{\prime} / g_{s i}\right) d i-\int_{1}^{2} \mu_{i} f_{u}^{\prime}\left(h_{i}^{u}\right) h_{i}^{u}\left(g_{u i}^{\prime} / g_{u i}\right) d i \\
& +\lambda \int_{1}^{2} n_{i}\left\{R_{i}-x_{i}\right\} d i+\lambda t \int_{1}^{2} n_{i} c_{1 i} d i+\beta_{s}\left\{\int_{1}^{2} g_{s i} h_{i}^{s} d i-H^{s}\right\}+\beta_{u}\left\{\int_{1}^{2} g_{u i} h_{i}^{u} d i-H^{u}\right\}
\end{aligned}
$$

the first-order-conditions are

$$
\begin{gathered}
v_{i}: n_{i}-\dot{u}_{i}-\lambda n_{i} \frac{\partial x_{i}}{\partial v_{i}}+\lambda t n_{i} \frac{\partial c_{1 i}}{\partial x} \frac{\partial x_{i}}{\partial v_{i}}=0 \\
R_{i}:-\mu_{i} \frac{d\left[f_{s}^{\prime}\left(h_{i}^{s}\right) h_{i}^{s}\left(g_{s i}^{\prime} / g_{s i}\right)\right]}{d h_{i}^{s}} \frac{\partial h_{i}^{s}}{\partial R_{i}}-\mu_{i} \frac{d\left[f_{u}^{\prime}\left(h_{i}^{u}\right) h_{i}^{u}\left(g_{u i}^{\prime} / g_{u i}\right)\right]}{d h_{i}^{u}} \frac{\partial h_{i}^{u}}{\partial R_{i}}+\lambda n_{i} \\
+\beta_{s} g_{s i} \frac{\partial h_{i}^{s}}{\partial R_{i}}+\beta_{u} g_{u i} \frac{\partial h_{i}^{u}}{\partial R_{i}}-\lambda n_{i} \frac{\partial x_{i}}{\partial R_{i}}+\lambda t n_{i} \frac{\partial c_{1 i}}{\partial x} \frac{\partial x}{\partial R_{i}}=0 \\
\mu_{1}=0 \text { and } \mu_{2}=0
\end{gathered}
$$

From the FOC of $v_{i}$, we will have $n_{i}-\dot{u}_{i}-\lambda n_{i} \frac{\partial x_{i}}{\partial v_{i}}+\lambda t n_{i} \frac{\partial c_{1 i}}{\partial x_{i}} \frac{\partial x_{i}}{\partial v_{i}}=0$

$$
n_{i}-\lambda n_{i} \frac{\partial x_{i}}{\partial v_{i}}=\dot{\mu}_{i}
$$

at $t=0$. By integrating both sides and using the definition of $\frac{\partial x_{i}}{\partial v_{i}}$ and $\mu_{1}=0$, we will have

$$
\int_{1}^{i} n_{i}\left\{1-\frac{\lambda}{U_{x}}\right\}=\mu_{i}
$$


From the first order condition of the revelation problem, $U_{x}\left(p_{1}, X\right) X^{\prime}(i)=Z_{R} R^{\prime}(i)$. This means that the sign of $X^{\prime}(i)$ and $R^{\prime}(i)$ are the same. Since $v(i)$ is strictly increasing, $X^{\prime}(i)$ and $R^{\prime}(i)$ must be increasing. When $X^{\prime}(i)$ is increasing, $\frac{\lambda}{U_{x}}$ is increasing. This implies that if at some $i^{* *}$, $1-\lambda / U_{x}=0$, then for any $i>i^{* *}, 1-\lambda / U_{x}<0$. However, $\mu_{2}=0$ from the FOC of $v_{2}$. This implies that $\mu_{1}$ is initially strictly positive until $i^{* *}$ and then it begins to decrease and reaches to zero at $i=2$. Therefore, $\mu_{i}>0$ for all $1<i<2$.

Now, we calculate the effect of increasing the commodity tax from $t=0$. By using the envelope theorem, we have

$$
\left.\frac{d W}{d t}\right|_{t=0}=\frac{\partial L}{\partial p_{1}} \frac{\partial p_{1}}{\partial t}+\lambda \int_{1}^{2} c_{1 i} n_{i} d i \lambda+\int_{1}^{2}\left[-\frac{\partial x_{i}}{\partial\left(p_{1}+t\right)}\right] d i
$$

where $\partial L / \partial p_{1}$ is

$$
\begin{aligned}
\frac{\partial L}{\partial p_{1}} & =\int_{1}^{2}\left\{-\mu_{i} \frac{d\left[f^{\prime}\left(h_{i}^{s}\right) h_{i}^{s}\left(g_{s i}^{\prime} / g_{s i}\right)\right]}{d h_{i}^{s}}+\beta_{s} g_{s i}\right\}\left\{\frac{d h_{i}^{s}}{d w_{i}^{s}} \frac{d w_{i}^{s}}{d p_{1}}+\frac{d h_{i}^{s}}{d w^{u}} \frac{d w_{i}^{u}}{d p_{1}}\right\} d i \\
& +\int_{1}^{2}\left\{-\mu_{i} \frac{d\left[f^{\prime}\left(h_{i}^{u}\right) h_{i}^{u}\left(g_{u i}^{\prime} / g_{u i}\right)\right]}{d h_{i}^{u}}+\beta_{u} g_{u i}\right\}\left\{\frac{d h_{i}^{u}}{d w_{i}^{u}} \frac{d w_{i}^{u}}{d p_{1}}+\frac{d h_{i}^{u}}{d w_{i}^{u}} \frac{d w_{i}^{u}}{d p_{1}}\right\} d i \\
& +\lambda \int_{1}^{2}\left[-\frac{\partial x_{i}}{\partial\left(p_{1}+t\right)}-\frac{\partial x_{i}}{\partial w_{i}^{s}} \frac{\partial w_{i}^{s}}{\partial p_{1}}-\frac{\partial x_{i}}{\partial w_{i}^{u}} \frac{\partial w_{i}^{u}}{\partial p_{1}}\right] n_{i} d i
\end{aligned}
$$

Note that $\partial x_{i} / \partial\left(p_{1}+t\right)=-\left(U_{p_{1}}\right) /\left(U_{x}\right)$. From the Roy's identity, $-\left(U_{p_{1}}\right) /\left(U_{x}\right)=c_{1 i}$. Therefore, $\lambda \int_{1}^{2} c_{1 i} n_{i} d i=\lambda \int_{1}^{2}\left(\frac{\partial x_{i}}{\partial p_{1}}\right) n_{i} d i$. In addition, $\frac{\partial x_{i}}{\partial w_{i}^{s}}=z_{w_{i}^{s}} / U_{x}$ and $\frac{\partial x_{i}}{\partial w^{u}}=z_{w^{u}} / U_{x}$ and $\frac{\partial x_{i}}{\partial R_{i}}=$ $Z_{R_{i}} / U_{x}$. Using the definition of $Z_{w_{i}^{s}}$ and $Z_{w^{u}}, \frac{\partial x_{i}}{\partial w_{i}^{s}}=-\alpha_{i} h_{i}^{s} / U_{x}, \frac{\partial x_{i}}{\partial w^{u}}=-\alpha_{i} h_{i}^{u} / U_{x}$ and $\frac{\partial x_{i}}{\partial R_{i}}=$ $\alpha_{i} / U_{x}$. Thus, $\int_{1}^{2} c_{1 i} n_{i} d i=\int_{1}^{2}\left[-\frac{\partial x_{i}}{\partial\left(p_{1}+t\right)} n_{i} d i\right.$. Therefore, we have

On the other hand, the FOC of $R_{i}$ at $t=0$ is that

$$
\begin{gathered}
\left\{-\mu_{i} \frac{d\left[f_{s}^{\prime}\left(h_{i}^{s}\right) h_{i}^{s}\left(g_{s i}^{\prime} / g_{s i}\right)\right]}{d h_{i}^{s}}+\beta_{s} g_{s i}\right\} \frac{\partial h_{i}^{s}}{\partial R_{i}}+\left\{-\mu_{i} \frac{d\left[f_{u}^{\prime}\left(h_{i}^{u}\right) h_{i}^{u}\left(g_{u i}^{\prime} / g_{u i}\right)\right]}{d h_{i}^{u}}+\beta_{u} g_{u i}\right\} \frac{\partial h_{i}^{u}}{\partial R_{i}} \\
+\lambda n_{i}=\lambda n_{i} \alpha_{i} / U_{x}
\end{gathered}
$$

Now, we will calculate $\lambda \int_{1}^{2}\left[-\frac{\partial x_{i}}{\partial w_{i}^{s}} \frac{\partial w_{i}^{s}}{\partial p_{1}}-\frac{\partial x_{i}}{\partial w_{i}^{u}} \frac{\partial w_{i}^{u}}{\partial p_{1}}\right] n_{i} d i$. Note that $-\lambda \frac{\partial x_{i}}{\partial w_{i}^{s}} n_{i}=\lambda \alpha_{i} n_{i} h_{i}^{s} / U_{x}$ and 
$-\lambda \frac{\partial x_{i}}{\partial w_{i}^{u}} n_{i}=\lambda \alpha_{i} n_{i} h_{i}^{u} / U_{x}$. From the FOC of $R_{i}, \lambda \int_{1}^{2}\left[-\frac{\partial x_{i}}{\partial w_{i}^{s}} \frac{\partial w_{i}^{s}}{\partial p_{1}}-\frac{\partial x_{i}}{\partial w_{i}^{u}} \frac{\partial w_{i}^{u}}{\partial p_{1}}\right] n_{i} d i$ is equal to

$$
\begin{aligned}
& \int_{1}^{2}\left\{\left(-\mu_{i} \frac{d\left[f_{s}^{\prime}\left(h_{i}^{s}\right) h_{i}^{s}\left(g_{s i}^{\prime} / g_{s i}\right)\right]}{d h_{i}^{s}}+\beta_{s} g_{s i}\right) \frac{\partial h_{i}^{s}}{\partial R_{i}}\right. \\
& \left.+\left(-\mu_{i} \frac{d\left[f_{u}^{\prime}\left(h_{i}^{u}\right) h_{i}^{u}\left(g_{u i}^{\prime} / g_{u i}\right)\right]}{d h_{i}^{u}}+\beta_{u} g_{u i}\right) \frac{\partial h_{i}^{u}}{\partial R_{i}}+\lambda n_{i}\right\} h_{i}^{s} \frac{\partial w_{i}^{s}}{\partial p_{1}} d i \\
& +\left\{\int_{1}^{2}\left(-\mu_{i} \frac{d\left[f_{s}^{\prime}\left(h_{i}^{s}\right) h_{i}^{s}\left(g_{s i} / g_{s i}\right)\right]}{d h_{i}^{s}}+\beta_{s} g_{s i}\right) \frac{\partial h_{i}^{s}}{\partial R_{i}}\right. \\
& \left.+\left(-\mu_{i} \frac{d\left[f_{u}^{\prime}\left(h_{i}^{u}\right) h_{i}^{u}\left(g_{u i}^{\prime} / g_{u i}\right)\right]}{d h_{i}^{u}}+\beta_{u} g_{u i}\right) \frac{\partial h_{i}^{u}}{\partial R_{i}}+\lambda n_{i}\right\} h_{i}^{u} \frac{\partial w_{i}^{u}}{\partial p_{1}} d i
\end{aligned}
$$

Therefore, $\partial L / \partial p_{1}$ becomes

$$
\begin{aligned}
\left.\frac{\partial L}{\partial p_{1}}\right|_{t=0} & =\left\{\int_{1}^{2}\left(-\mu_{i} \frac{d\left[f_{s}^{\prime}\left(h_{i}^{s}\right) h_{i}^{s}\left(g_{s}^{\prime} / g_{s}\right)\right]}{d h_{i}^{s}}+\beta_{s} g_{i}^{s}\right)\left[\left\{\frac{d h_{i}^{s}}{d w_{i}^{s}}+h_{i}^{s} \frac{\partial h_{i}^{s}}{\partial R_{i}}\right\} \frac{d w_{i}^{s}}{d p_{1}}+\left\{\frac{d h_{i}^{s}}{d w_{i}^{u}}+h_{i}^{u} \frac{\partial h_{i}^{s}}{\partial R_{i}}\right\} \frac{d w_{i}^{u}}{d p_{1}}\right] d i\right. \\
& -\int_{1}^{2}\left(-\mu_{i} \frac{d\left[f_{u}^{\prime}\left(h_{i}^{u}\right) h_{i}^{u}\left(g_{u}^{\prime} / g_{u}\right)\right]}{d h_{i}^{u}}+\beta_{u} g_{i}^{u}\right)\left[\left\{\frac{d h_{i}^{u}}{d w_{i}^{s}}+\frac{\partial h_{i}^{u}}{\partial R_{i}} h_{i}^{s}\right\} \frac{d w_{i}^{s}}{d p_{1}}+\left\{\frac{d h_{i}^{u}}{d w_{i}^{u}}+\frac{\partial h_{i}^{u}}{\partial R_{i}} h_{i}^{u}\right\} \frac{d w_{i}^{u}}{d p_{1}}\right] d i \\
& +\int_{1}^{2}\left[-\lambda \frac{\partial x_{i}}{\partial\left(p_{1}+t\right)}+\int_{1}^{2} \lambda n_{i} h_{i}^{s} \frac{\partial w_{i}^{s}}{\partial p_{1}} d i+\int_{1}^{2} \lambda n_{i} h_{i}^{u} \frac{\partial w_{i}^{u}}{\partial p_{i}} d i\right\}
\end{aligned}
$$

Note that $\int_{1}^{2} \lambda n_{i} h_{i}^{s} \frac{\partial w_{i}^{s}}{\partial \sigma} d i+\int_{1}^{2} \lambda n_{i} h_{i}^{u} \frac{\partial w^{u}}{\partial \sigma} d i=\lambda y^{1}$ from the argument in the previous subsection. Therefore, $+\int_{1}^{2}\left[-\lambda \frac{\partial x_{i}}{\partial\left(p_{1}+t\right)}+\int_{1}^{2} \lambda n_{i} h_{i}^{s} \frac{\partial w_{i}^{s}}{\partial p_{1}} d i+\int_{1}^{2} \lambda n_{i} h_{i}^{u} \frac{\partial w_{i}^{u}}{\partial p_{i}} d i=0\right.$. We have

$$
\begin{aligned}
\frac{\partial L}{\partial p_{1}} & =\left\{\int_{1}^{2}\left(-\mu_{i} \frac{d\left[f_{s}^{\prime}\left(h_{i}^{s}\right) h_{i}^{s}\left(g_{s}^{\prime} / g_{s}\right)\right]}{d h_{i}^{s}}+\beta_{s} g_{i}^{s}\right)\left[\frac{\partial \widetilde{h}_{i}^{s}}{\partial w_{i}^{s}} \frac{d w_{i}^{s}}{d p_{1}}+\frac{\partial \widetilde{h}_{i}^{s}}{\partial w_{i}^{u}} \frac{d w_{i}^{u}}{d p_{1}}\right] d i\right. \\
& \left.+\int_{1}^{2}\left(-\mu_{i} \frac{d\left[f_{u}^{\prime}\left(h_{i}^{u}\right) h_{i}^{u}\left(g_{u}^{\prime} / g_{u}\right)\right]}{d h_{i}^{u}}+\beta_{u} g_{i}^{u}\right)\left[\frac{\partial \widetilde{h}_{i}^{u}}{\partial w_{i}^{s}} \frac{d w_{i}^{s}}{d p_{1}}+\frac{\partial \widetilde{h}_{i}^{u}}{\partial w_{i}^{u}} \frac{d w_{i}^{u}}{d p_{1}}\right] d i\right\}
\end{aligned}
$$

From the FOC of $H^{s}$ and $H^{u}, \beta_{s}=\frac{\partial W}{\partial p_{1}} \frac{\partial p}{\partial H^{s}}$ and $\beta_{u}=\frac{\partial W}{\partial p_{1}} \frac{\partial p}{\partial H^{u}}$. Thus,

$$
\begin{aligned}
\frac{\partial L}{\partial p_{1}} & =\int_{1}^{2}\left(-\mu_{i} \frac{d\left[f_{s}^{\prime}\left(h_{i}^{s}\right) h_{i}^{s}\left(g_{s}^{\prime} / g_{s}\right)\right]}{d h_{i}^{s}}\right)\left[\frac{\partial \widetilde{h}_{i}^{s}}{\partial w_{i}^{s}} \frac{d w_{i}^{s}}{d p_{1}}+\frac{\partial \widetilde{h}_{i}^{s}}{\partial w_{i}^{u}} \frac{d w_{i}^{u}}{d p_{1}}\right] d i \\
& +\int_{1}^{2}\left(-\mu_{i} \frac{d\left[f_{u}^{\prime}\left(h_{i}^{u}\right) h_{i}^{u}\left(g_{u}^{\prime} / g_{u}\right)\right]}{d h_{i}^{u}}\right)\left[\frac{\partial \widetilde{h}_{i}^{u}}{\partial w_{i}^{s}} \frac{d w_{i}^{s}}{d p_{1}}+\frac{\partial \widetilde{h}_{i}^{u}}{\partial w_{i}^{u}} \frac{d w_{i}^{u}}{d p_{1}}\right] d i \\
& +\frac{\partial L}{\partial p_{1}}\left(\int_{1}^{2} \frac{\partial p}{\partial H^{s}} g_{i}^{s}\left[\frac{\partial \widetilde{h}_{i}^{s}}{\partial w_{i}^{s}} \frac{d w_{i}^{s}}{d p_{1}}+\frac{\partial \widetilde{h}_{i}^{s}}{\partial w_{i}^{u}} \frac{d w_{i}^{u}}{d p_{1}}\right] d i+\int_{1}^{2} \frac{\partial p}{\partial H^{u}} g_{i}^{u}\left[\frac{\partial \widetilde{h}_{i}^{u}}{\partial w_{i}^{s}} \frac{d w_{i}^{s}}{d p_{1}}+\frac{\partial \widetilde{h}_{i}^{u}}{\partial w_{i}^{u}} \frac{d w_{i}^{u}}{d p_{1}}\right] d i\right)
\end{aligned}
$$


Solving for $\frac{\partial L}{\partial p_{1}}$, we have

$$
\begin{aligned}
\frac{\partial L}{\partial p_{1}}= & \frac{1}{\triangle}\left\{\int_{1}^{2}\left(-\mu_{i} \frac{d\left[f_{s}^{\prime}\left(h_{i}^{s}\right) h_{i}^{s}\left(g_{s}^{\prime} / g_{s}\right)\right]}{d h_{i}^{s}}\right)\left[\frac{\partial \widetilde{h}_{i}^{s}}{\partial w_{i}^{s}} \frac{d w_{i}^{s}}{d p_{1}}+\frac{\partial \widetilde{h}_{i}^{s}}{\partial w_{i}^{u}} \frac{d w_{i}^{u}}{d p_{1}}\right] d i\right. \\
& \left.\int_{1}^{2}\left(-\mu_{i} \frac{d\left[f_{u}^{\prime}\left(h_{i}^{u}\right) h_{i}^{u}\left(g_{u}^{\prime} / g_{u}\right)\right]}{d h_{i}^{u}}\right)\left[\frac{\partial \widetilde{h}_{i}^{u}}{\partial w_{i}^{s}} \frac{d w_{i}^{s}}{d p_{1}}+\frac{\partial \widetilde{h}_{i}^{u}}{\partial w_{i}^{u}} \frac{d w_{i}^{u}}{d p_{1}}\right] d i\right\}
\end{aligned}
$$

where $\triangle=1-\left(\int_{1}^{2} \frac{\partial p}{\partial H^{s}} g_{i}^{s}\left[\frac{\partial \widetilde{h}_{i}^{s}}{\partial w_{i}^{s}} \frac{d w_{i}^{s}}{d p_{1}}+\frac{\partial \widetilde{h}_{i}^{s}}{\partial w_{i}^{u}} \frac{d w_{i}^{u}}{d p_{1}}\right] d i+\int_{1}^{2} \frac{\partial p}{\partial H^{u}} g_{i}^{u}\left[\frac{\partial \widetilde{h}_{i}^{u}}{\partial w_{i}^{s}} \frac{d w_{i}^{s}}{d p_{1}}+\frac{\partial \widetilde{h}_{i}^{u}}{\partial w_{i}^{u}} \frac{d w_{i}^{u}}{d p_{1}}\right] d i\right)>0$.

$$
\begin{aligned}
\frac{\partial W}{\partial p_{1}}= & \frac{1}{\triangle}\left\{\int_{1}^{2}\left(-\mu_{i}\left[\frac{f_{s}^{\prime \prime}\left(h_{i}^{s}\right) h_{i}^{s}}{f_{s}^{\prime}\left(h_{i}^{s}\right)}+1\right]\left(g_{s}^{\prime} / g_{s}\right)\right)\left[f_{s}^{\prime} \frac{\partial \widetilde{h}_{i}^{s}}{\partial w_{i}^{s}} \frac{d w_{i}^{s}}{d p_{1}}+f_{s}^{\prime} \frac{\partial \widetilde{h}_{i}^{s}}{\partial w_{i}^{u}} \frac{d w_{i}^{u}}{d p_{1}}\right] d i\right. \\
& \left.\int_{1}^{2}\left(-\mu_{i}\left[\frac{f_{u}^{\prime \prime}\left(h_{i}^{u}\right) h_{i}^{u}}{f_{u}^{\prime}\left(h_{i}^{u}\right)}+1\right]\left(g_{u}^{\prime} / g_{u}\right)\right)\left[f_{u}^{\prime} \frac{\partial \widetilde{h}_{i}^{u}}{\partial w_{i}^{s}} \frac{d w_{i}^{s}}{d p_{1}}+f_{u}^{\prime} \frac{\partial \widetilde{h}_{i}^{u}}{\partial w_{i}^{u}} \frac{d w_{i}^{u}}{d p_{1}}\right] d i\right\}
\end{aligned}
$$

From the definition of $\widetilde{h}_{i}^{s}$ and $\widetilde{h}_{i}^{u}$, we have

$$
f_{s}^{\prime}\left(\widetilde{h}_{i}^{s}\right) \frac{\partial \widetilde{h}_{i}^{s}}{\partial w_{i}^{s}}+f_{u}^{\prime}\left(\widetilde{h}_{i}^{u}\right) \frac{\partial \widetilde{h}_{i}^{u}}{\partial w_{i}^{s}}=0 \text { and } f_{u}^{\prime}\left(\widetilde{h}_{i}^{s}\right) \frac{\partial \widetilde{h}_{i}^{s}}{\partial w_{i}^{u}}+f_{u}^{\prime}\left(\widetilde{h}_{i}^{u}\right) \frac{\partial \widetilde{h}_{i}^{u}}{\partial w_{i}^{u}}=0
$$

Therefore, we have

$$
\begin{aligned}
\left.\frac{\partial L}{\partial p_{1}}\right|_{t=0} & =-\frac{1}{\triangle}\left\{\int_{1}^{2} \mu_{i}\left(\left[\frac{f_{s}^{\prime \prime}\left(h_{i}^{s}\right) h_{i}^{s}}{f_{s}^{\prime}\left(h_{i}^{s}\right)}+1\right]\left(g_{s}^{\prime} / g_{s}\right)-\left[\frac{f_{u}^{\prime \prime}\left(h_{i}^{u}\right) h_{i}^{u}}{f_{u}^{\prime}\left(h_{i}^{u}\right)}+1\right]\left(g_{u}^{\prime} / g_{u}\right)\right) f_{s}^{i}\left[\frac{\partial \widetilde{h}_{i}^{s}}{\partial w_{i}^{s}} \frac{d w_{i}^{s}}{d p_{1}}+f_{s}^{\prime} \frac{\partial \widetilde{h}_{i}^{s}}{\partial w_{i}^{u}} \frac{d w_{i}^{u}}{d p_{1}}\right] d i\right\} \\
& =-\frac{1}{\triangle}\left\{\int_{1}^{2} \mu_{i}\left[\gamma^{s}\left(g_{s}^{\prime} / g_{s}\right)-\gamma^{u}\left(g_{u}^{\prime} / g_{u}\right)\right] f_{s}^{i}\left[\frac{\partial \widetilde{h}_{i}^{s}}{\partial w_{i}^{s}} \frac{d w_{i}^{s}}{d p_{1}}+f_{s}^{\prime} \frac{\partial \widetilde{h}_{i}^{s}}{\partial w_{i}^{u}} \frac{d w_{i}^{u}}{d p_{1}}\right] d i\right\}
\end{aligned}
$$

Using the definition of $\partial p_{1} / \partial H^{s}$ and $\partial p_{1} / \partial H^{u}$, This implies that $d W / d t$ is equal to

$$
\frac{d W}{d t_{1}}=-\Psi_{2}\left\{\int_{1}^{2} \mu_{i}\left[\gamma^{s}\left(g_{s}^{\prime} / g_{s}\right)-\gamma^{u}\left(g_{u}^{\prime} / g_{u}\right)\right] f_{s}^{i}\left[\frac{\partial \widetilde{h}_{i}^{s}}{\partial w_{i}^{s}} \frac{d w_{i}^{s}}{d p_{1}}+f_{s}^{\prime} \frac{\partial \widetilde{h}_{i}^{s}}{\partial w_{i}^{u}} \frac{d w_{i}^{u}}{d p_{1}}\right] d i\right\}
$$

where

$$
\Psi_{2}=\frac{-R D_{p}}{R D_{p_{1}}-R S_{p_{1}}-R S_{H^{s}} \int_{1}^{2} g_{i}^{s}\left[\frac{\partial \widetilde{h}_{i}^{s}}{\partial w_{i}^{s}} \frac{d w_{i}^{s}}{d p_{1}}+\frac{\partial \widetilde{h}_{i}^{s}}{\partial w_{i}^{u}} \frac{d w_{i}^{u}}{d p_{1}}\right] d i-R S_{H^{u}} \int_{1}^{2} g_{i}^{u}\left[\frac{\partial \widetilde{h}_{i}^{u}}{\partial w_{i}^{s}} \frac{d w_{i}^{s}}{d p_{1}}+\frac{\partial \widetilde{h}_{i}^{u}}{\partial w_{i}^{u}} \frac{d w_{i}^{u}}{d p_{1}}\right] d i}
$$

From the condition of the comparative advantage, $\gamma^{s}\left(g_{s}^{\prime} / g_{s}\right)-\gamma^{u}\left(g_{u}^{\prime} / g_{u}\right)>0$. In addition, $\Psi_{2}<0$. Thus, $\frac{d W}{d t}>0$. 


\section{References}

[1] Atkinson, A. and Joseph E. Stiglitz Lectures on Public Economics , McGraw Hill, 1980.

[2] Atkinson, A. and Stiglitz, Joseph E., "The Design of Tax Structure: Direct versus Indirect Taxation," Journal of Public Economics 6, July-Aug. 1976, pp 55-75.

[3] Berge, Claude Topological Spaces, New York, Macmillan, 1963.

[4] Boadway,Robin and Katherine Cuff, "A Minimum Wage Can Be Welfare-Improving and Employment-Enhancing," European-Economic-Review 45(3), March 2001, pages 553-76.

[5] Diamond, Peter and James Mirrlees, 1971, "Optimal Taxation and Public Production," American Economic Review, 61, pp8-27 and pp 261-278.

[6] DiNardo,John and Justin Tobias, 2001, "Nonparametric Density and Regression Estimation," Journal of Economic Perspectives 15(4), Fall 2001, pp 11-28.

[7] Fudenberg, Drew and Jean Tirole, Game Theory, MIT Press, 1992.

[8] Mirrlees, James A.,1971, "An Exploration in the Theory of Optimum Income Taxation," Review of Economic Studies, 38, pp 175-208.

[9] Naito, Hisahiro, 1996, "Tariff As A Device to Relax the Incentive Problem of a Progressive Income Tax System," Research Seminar of International Economics Working Papers, No 391, The Department of Economics and School of Public Policy,http://www.spp.umich.edu/rsi, The University of Michigan.

[10] Naito, Hisahiro, 1999a, "Re-examination of Uniform Commodity Taxes under A Non-linear Income Tax System and Its Implication for Production Efficiency," February 1(2),. Journal of Public Economics, pp65-88

[11] Stiglitz,Joseph, 1982, "Self-Selection and Pareto Efficient Taxation," Journal of Public Economics, 17, pp 213-240. 
[12] Samuelson, Paul A., 1949, "International Factor-Price Equalisation Once Again", The Economic Journal, pp 181-197.

[13] Saez, Emanuel, 2002, "Direct or Indirect Instruments for Redistribution: Short-run versus Long-Run", Journal of Public Economics, Forthcoming

[14] Stolper, Wolfgang and Paul Samuelson, 1941, "Protection and Real Wages," Review of Economic Studies, 9, pp 58-73.

[15] Tobias, L. Justin, "Are Returns to Schooling Concentrated Among the Most Able? A Semiparametric Analysis of the Ability Earnings Relationships", Oxford Bulletin of Economics and Statistics, 2003, 65, pp 1-29. 